\title{
Learn from Each Other: A Peer-Teaching Model
}

\author{
Adiv Gal ${ }^{\star \star}$, Orna Fallik ${ }^{1}$ \\ ${ }^{1}$ Kibbutzim College of Education Technology and the Arts, ISRAEL \\ *Corresponding Author: adiv.gal@smkb.ac.il
}

Citation: Gal, A., \& Fallik, O. (2021). Learn from each other: A peer-teaching model. Interdisciplinary Journal of Environmental and Science Education, 17(3), e2242. https://doi.org/10.21601/ijese/10896

\begin{tabular}{|c|c|}
\hline ARTICLE INFO & ABSTRACT \\
\hline $\begin{array}{l}\text { Received: } \\
26 \text { December } 2020\end{array}$ & $\begin{array}{l}\text { The aim of the study was to examine the degree of competence of the teaching-learning goals as } \\
\text { formulated by the elementary-school staff members and the expression of these goals in science } \\
\text { classes, in which peer teaching takes place, from the students' point of view. As part of this peer } \\
\text { teaching, fellow teachers who were assigned from among the students were in charge of teaching the } \\
\text { rest of the class that had been divided into groups of four to five. The research adapted mix-methods, } \\
\text { which helped to answer the following questions: a). What are the teaching-learning goals of the school } \\
\text { staff at Tzemach School that engages in the peer teaching approach combined with traditional } \\
\text { teaching? b). How are teaching-learning goals formulated by the peer-teaching school staff in science } \\
\text { classes described from the students' point of view? The research tools used included interviews with } \\
\text { teachers, interviews with group leaders, focus groups, observations, and drawing analyses. The findings } \\
\text { indicate that there is a gap between teachers' perceptions of peer teaching and students' perceptions } \\
\text { of peer teaching. Teachers placed greater emphasis on the cognitive aspects, while the students paid } \\
\text { more attention to the social-emotional and behavioral aspects. Despite these gaps, students are } \\
\text { interested in continuing to study through peer teaching, provided the presence of the accompanying } \\
\text { teacher is more significant. Based on the existing model for peer teaching at Tzemach School and } \\
\text { according to the findings of the study, a desirable model for integrating peer teaching was developed, } \\
\text { which can aid in implementation of the apnroach for anv age and in anv another scholastic subiect }\end{array}$ \\
\hline
\end{tabular}

Keywords: peer-teaching model, peer teaching, fellow teacher, student drawings, hidden curriculum

\section{INTRODUCTION}

Motivation to study science is not high among adolescent students (Osborne et al., 2003; Potvin \& Hasni, 2014; Vedder-Weiss \& Fortus, 2011). One of the reasons for the decline in student motivation to study science is the lack of suitable science teachers who are able to draw students towards this discipline (Osborne et al., 2003). In many cases, teachers who are not at all trained in science actually teach it (Espinoza et al., 2018; Sutcher et al., 2019). These teachers do not have the pedagogical knowledge and skills to teach science (Arviv-Elyashiv \& Gal, 2017; Espinoza et al., 2018) often using a teacher-central approach and rarely a diverse pedagogy method that overrides the relative benefits of science teaching, which should be accompanied by experiments, observations of phenomena, extracurricular learning, learning through science and technology projects to experience and understand the behavior of the scientific world (Kubiatko et al., 2017). As part of the attempt to reverse the trend of declining motivation to study science among students, various attempts, such as financial compensation, professional guidance and support, are being made (Gal, 2020). One of the attempts to resolve the shortage of good teachers (Karamaroudis et al., 2020) and draw students to the science discipline is through social learning, such as activating peer teaching (PT) (Lim,

Copyright (C) 2021 by Author/s and Licensed by Veritas Publications Ltd., UK. This is an open access article distributed under the Creative Commons Attribution License which permits unrestricted use, distribution, and reproduction in any medium, provided the original work is properly cited. 
2003; Olle \& Durning, 2007). Usually, in PT, in each small group of students there is a student who is assigned to be the head of a group and is trained to teach their fellow students. This group leader is also referred to as a "fellow teacher" (Boud, 2001). It is assumed that fellow teachers are able to connect their peers to science as well as speak the language of students (Boud \& Alison, 2007; Lockspeiser et al., 2008). On the other hand, adopting such a learningteaching, based on fellow teachers raises pedagogical and educational questions: Are students able to teach students? Does relatively short training qualify them to teach their classmates? In their training, do fellow teachers address other aspects of teaching in addition to the cognitive aspects, such as social-behavioral and emotional and value-based aspects, that form the basis of learning (Tyng et al., 2017)? This study has attempted to answer these questions and has focused on examining a case study of PT in a model of fellow teachers teaching their classmates a science study unit in Tzemach School, examining the goals set by the school staff and how these are implemented during PT. To the best of our knowledge there is no information about PT in elementary schools and particularly in the science discipline. Therefore, another goal of this research is to expand the research on the above-mentioned aspects.

\section{LITERATURE REVIEW}

\section{The Sociocultural Theory}

The peer-teaching strategy is based on cooperation and social learning included in Vygotsky's Sociocultural Theory (1978). According to this theory the learning process includes the subject, the learning person, an object that is the object of the person's activity and the mediating artifact that includes social tools that mediate between the person learning and the object of his activity. According to Vygotsky, social mediation is of great importance in the learner's ability to express high-level mental functions such as the ability to draw conclusions and the ability to solve problems. Vygotsky also refers to the existing ZPD (Zone of Proximal Development) gap between the learning outcomes of an individual student, and the learning outcomes, which are the result of social interactions that lead to the narrowing of this gap. The social interactions are based on a relationship between the learner and an adult or on a relationship created between the learner and his peers with different knowledge and/or skills that allow the creation of mediation that helps reduce ZPD (Case,
1985; Vygotskiĭ, 1978). PT is an example of a teaching method based on this theory.

\section{Peer Teaching}

PT serves as a strategy for learning knowledge and skills in a collaborative way in which students teach each other, and is an example of a teaching method that is based on Vygotsky's theory (Engels et al., 2018; Nind et al., 2020). In this learning, one of the students is usually defined as the fellow teacher who teaches the rest of his group of students under the supervision of an experienced teacher (Topping, 2005). PT is not one distinct educational strategy (Boud, 2001) and there are diverse ways to implement it (Griffiths et al., 1995), e.g., in pairs, with one student teaching a fellow student or in multi-participant groups (Lockspeiser et al., 2008; Secomb, 2008). Learning can be conducted as equal learning or with a fellow teacher in charge of learning (Boud, 2001); students can be of the same age or of different ages in the same learning group (Lockspeiser et al., 2008). In some cases, use of PT can compensate the shortage of teachers in the school (Korner \& Hopf, 2015). In higher education using PT might help learn in small groups instead of teaching in large lecture halls (Olle \& Durning, 2007). PT is believed to help students learn effectively and is an important addition to the repertoire of teaching and learning activities that can improve the quality of education (Boud, 2001) but is not a substitute for teaching and activities designed and conducted by teachers trained for teaching. In order for it to be successful, it is not enough to focus on the cognitive aspect, as the social aspect plays a significant role in the success of PT (Engels et al., 2018; Räisänen et al., 2020).

There are many advantages for PT such as: a). Students can help their peers learn while at the same time learn on their own; b). There is no "cognitive distance" between teachers and students; they use everyday language that is familiar to them (Lockspeiser et al., 2008) and thus the learners and fellow teacher benefit by improving the academic performance of pupils, creating and cultivating social bonds between the fellow teacher and the students in his/her group who are in the same class on a day-today basis, sharing the same process and more (Boud, 2001). On the other hand, there are challenges of PT such as concerns about the level of the content being taught if appropriate training has not been conducted for the fellow teachers and lack of systematicity and the construction of learning (Olle \& Durning, 2007). 
Social-Emotional Learning

In addition to the cognitive challenges in school, schools must also provide a socially and emotionally positive learning environment (Neth et al., 2020). The combination of this learning is called social-emotional learning - SEL (Newman, 2020; Yang et al., 2020). Students, the citizens of tomorrow, must experience a process in which knowledge is acquired while applied effectively and while examining the attitudes and skills necessary to manage their emotions, such as dealing with uncertainty, dealing with problem solving, empathy and compassion for others, maintaining positive relationships and making responsible decisions (Omasta et al., 2020; Pinchumphonsang \& Chanchalor, 2020). Moreover, the students need to deal with mental abilities related to processing and responding to emotions such as using empowering emotions, and motivating effective behavior (Pinchumphonsang \& Chanchalor, 2020).

Elementary school students, who are the objective of this study, are considered to be young adolescents who are particularly sensitive to SEL experiences. Moreover, studies indicate that the most prominent learning experiences for adolescents are those that include messages that harness adolescents' deepest motives - their desire to gain respect and status in the eyes of peers or adults they value. SEL experiences shape their adolescence and personal identity. Students acquire social knowledge and understand their relationships and thus shape their values and beliefs (Cherewick et al., 2021). Important SEL has been found to occur through the active processes of adolescents struggling with challenges, problem solving, and reflective experiential learning (Orson et al., 2020). Therefore, the use of a peer-teaching strategy enables the development of self-knowledge, reciprocity within peer relationships, and influences identity development (Nind et al., 2020), resulting in SEL experiences.

\section{Objectives of Teaching-Learning Versus School Performance}

Different schools design their vision in light of the educational goals that are constructed in various aspects as part of their curriculum. In this context, a number of questions arise: Does the school staff know what these goals are? Are the classes planned according to these goals? Are all or only some of the goals implemented in the school? What is the connection between the goals that are implemented and those that are not? How does the school staff and teachers choose the goals for which the classes are planned? Is the teacher aware that in addition to the stated curriculum there is also a hidden curriculum that represents the learner's place at a given moment? The term "hidden curriculum" refers to values, behaviors, unspoken or implied as well as unspoken or implied procedures and norms that exist in the educational setting (Alsubaie, 2015). Such programs can be transmitted without conscious intention between the teachers and the students; they can play a positive or negative role and therefore it is essential that the per-teacher be aware of this. For example, in PT, the fellow teacher has the task of teaching the content of a particular unit and is motivated to execute this. However, is $s /$ he aware that each of the teammates is currently in his/her own personal place? For example, one student may be afraid to reveal his/her lack of knowledge in the group to the other group students, in contrast to another student who is happy to stand out in such a situation. The hidden curriculum is also included in the school atmosphere and culture.

In order to understand whether the science teacher had indeed prepared the fellow teacher for the open and covert curriculum of Tzemach School, the school staff was examined, as well as their knowledge of the visible curriculum, school goals and personal goals of the teachers. The perceptions of these findings of both the fellow teacher and the pupils learning in this perteaching environment were compared.

The literature recognizes the advantages and disadvantages of PT as part of SEL, especially in adulthood, but addresses very little if any of the ages of elementary-school students in the science discipline in particular. We also did not find a comparison in the literature that examines the realization of the goals of the school staff in PT in accordance with the point of view of students in general and students in elementary school in particular. Moreover, the literature rarely addresses the point of view of young students experiencing teaching peers of aspects of SEL. Hence, this study serves to narrow the gap between PT in the science discipline in elementary school when addressing aspects of SEL from the perspective of the school staff compared to the perception of the students.

\section{Research Questions}

In this study, we have addressed the following two questions:

1. What are the teaching-learning goals of the school staff at Tzemach School that 
adopted PT in combination with traditional learning from their perspective?

2. How are the teaching-learning goals formulated by the school staff at Tzemach School manifested in science classes taught through PT, from the students' perspective?

\section{Research Context - Tzemach School}

Tzemach School is an elementary school where $1^{\text {st }}-6^{\text {th }}$ grade students' study within the Montessori philosophy. The school is located in a rural area in central Israel. There is a petting zoo in the large schoolyard and it is near a nature reserve located on the shores of the Mediterranean Sea that serve as learning environments. Learning is based on mixedage classes, thus $1^{\text {st }}-3^{\text {rd }}$-grades students' study together in the same class, as do $4^{\text {th }}-6^{\text {th }}$-grades students. Students study according to their personal progress and not according to age group. In keeping with the Montessori spirit (Marshall, 2017), the school declares that it promotes a variety of programs that are designed to empower students. As part of these programs, the school attempts to foster a process of shaping an independent pupil who manages his/her learning while attempting to develop meta-cognitive thinking towards learning as well as stimulating their natural curiosity. The teacher serves as a mediator and accompanies the learning and personal processes that the students experience. Activities in school are based on an active and changing learning environment, which includes learning centers for independent learning and are open to teamwork and personal student initiative. Teaching methods in the school are varied, such as the flipped classroom, Outside Learning, science experiments and observations. Some students lead the learning processes in all areas of PT. In our case study, the learned science unit focused on the holistic examination of rocks as part of the geology component of science learning and included a reference to the way rocks are formed, the properties of rocks and how rocks are made use of by people.

\section{An Existing Model for Peer Teaching in Science Class}

Tzemach School chose to apply a model of PT (Figure 1 ) in science class in one of the $4^{\text {th }}-6^{\text {th }}$ grades. The model was led by science teachers. The model has seven steps:

Step 1. Selection of fellow teachers: About six months before starting PT, the fellow teachers chosen to serve as teachers for their classmates were selected. The science teacher asked students to volunteer for the position. Afterwards, the science teacher met with the volunteers and explained to them what was expected of each fellow teacher. At the end of the process, each student who decided to volunteer and become a fellow teacher was given the role. These fellow teachers were exposed to the learning content and studied it thoroughly with the science teacher. In addition, the fellow teachers and the science teacher constructed a weekly detailed curriculum that was recorded in a workbook that they edited together.

Step 2. Receiving the syllabus: About a week before each class, the science teacher resent the study material intended for the next class. The fellow teachers were expected to study the content themselves before the class. Self-learning is based on the personal responsibility of the group leaders and on the assumption that editing the textbook they prepared together with the accompanying teacher will form the basis for their learning.

Step 3. Preliminary morning meeting: About a quarter of an hour before the start of the class, a preliminary meeting was held in which the fellow teachers met with the science teacher for clarifications and final questions. Sometimes, during this meeting, changes were made to the class plan.

Step 4. Opening of the class by the science teacher: The science teacher began the class with an introduction that included a statement on the topic of the class.

Step 5. During the class: The students and fellow teachers began to study. The science teacher as well as the other two teachers moved between the groups for support when needed. The students studied in groups until the end of the class.

Step 6. Each fellow teacher meets with the science teacher: About a month after PT was started, the science teacher met each of the fellow teachers separately for feedback. They talked about the challenges and successes of each of fellow teachers.

Step 7. Participant reflection: At the end of the study unit, a concluding session was held that included the science teacher, the students, the fellow teachers, and the homeroom teachers. It should be noted that the cognitive aspects of learning were the main issues that were discussed. The socio-behavioral and emotional aspects were discussed during Steps 3, 5 and 7 . They also discussed additional activities such as reflection on the peer teaching process as well as pedagogical guidance and assessment method issues. 


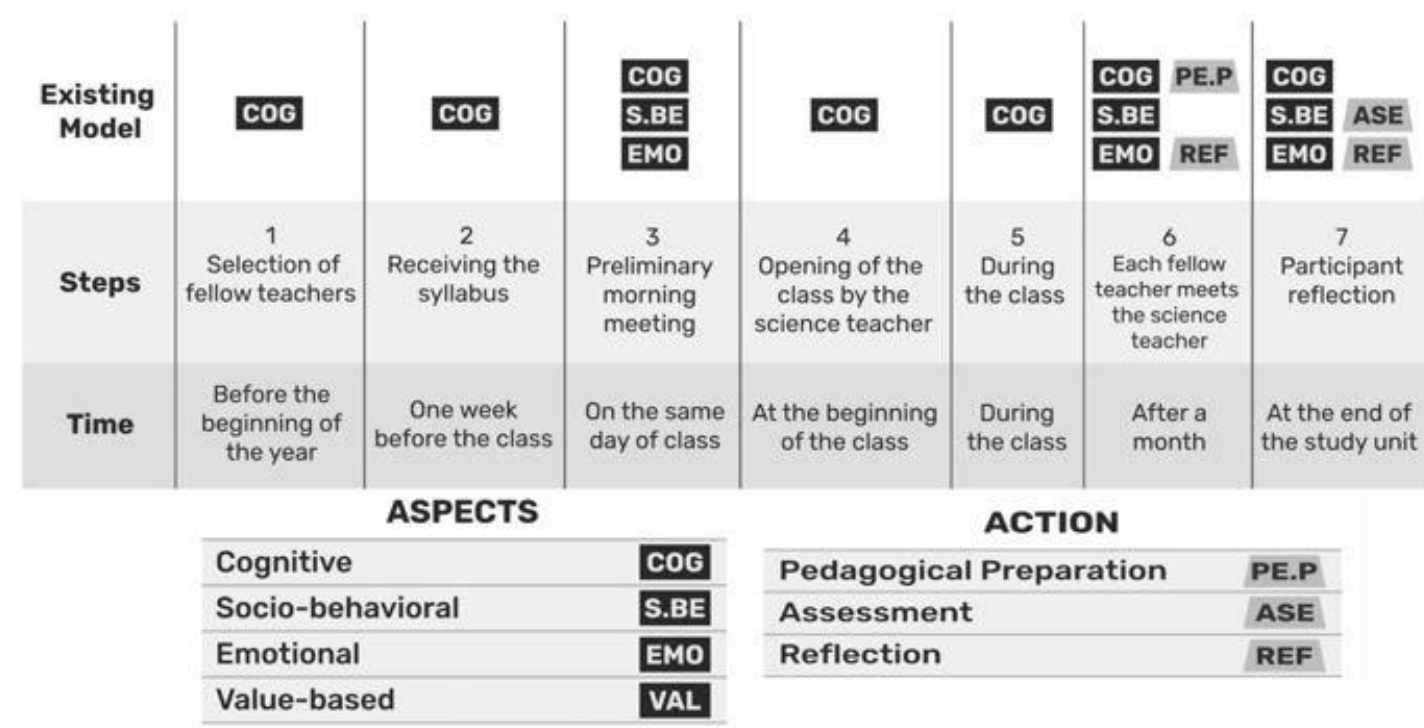

Figure 1. Peer teaching existing model at Tzemach School

\section{Population}

Seven school staff members participated in this research (the school principal, five homeroom teachers and a science teacher). In addition, 76 students aged 9-11 years old, divided into two classes; the first class included 37 students who studied science through PT (experiment group) and the second class included 39 students who studied science in the traditional way (control group). The first class was divided into seven groups. Each group included four students of different ages and one fellow teacher.

\section{METHODS}

This study combined the qualitative research with the quantitative research approach (Wiersma \& Jurs, 2005). In this way, it allowed for the presentation of the research problem through more explicit and in-depth data (Fraenkel et al., 2012). The qualitative research was based on Grounded Theory (Glaser \& Strauss, 1967) and included open-ended and in-depth interviews with the school staff and with seven fellow teachers, discussion with three Focus Group students and fellow teachers, students' drawings, class observations and an observation in a joint reflection discussion for teachers and students that participated in PT.

\section{Interviews}

All interviews were recorded, transcribed and analyzed. The analysis included: Preliminary analysis open coding (Strauss \& Corbin, 1990) that divided the entire text into inductive categories and a secondary analysis that divided those categories into categories that corresponded with each other by creating links between them (Pidgeon \& Henwood, 1996), and attaching quotes (references) of the interviewees to these categories. From the school staff interviews, teaching-learning goals were extracted. These goals were reformulated into main goals that were then divided into four categories: Cognitive aspect; Socialbehavioral aspect; Emotional aspect and Value-based aspect. These goals were compared with the students' expressions (fellow teachers and focus groups) that addressed the implementation of these goals in the same four aspects. Two comparisons were made: a numerical comparison that included the number of expressions for each of the aspects among the school staff (teaching-learning goals) and the number of expressions students iterated and represented the expression of these goals in the classes in which PT occurred. A qualitative comparison was also made in which the students' expressions were aligned with the teachers' expressions in all these categories. At the end of the process, a theoretical analysis was recorded according to the categories that emerged from the field. It is worth noting that the analysis of the interviews of the school staff was initially carried out inductively for three of the interviews, in which the teaching-learning goals were found (Shkedi, 2004, 2005). Based on these, the remaining four interviews of the school staff were analyzed (deductive analysis).

\section{Focus Groups}

Interviews were held in three focus groups, each of them including approximately nine students and the fellow teachers. The focus groups allowed observation of a large number of interactions between students in 
a limited time, based on questions in the PT context (Franz, 2015). The interviews were recorded, transcribed and analyzed similarly to the interview analyses. The teaching-learning goals of the school staff were compared with the statements that were found in those focus groups.

\section{Student Drawings}

In this study, the Phenomenological Analysis method was used in the interpretive approach (Van Manen, 2016). Using this method makes it possible to clarify the meaning of phenomena in their lives as experienced by participants in the studies (Van Manen, 2016). The method was originally intended for analyzing texts, but in recent decades many studies have employed this method using drawings that are considered visual text (Alerby, 2000; Van Manen, 2016). Therefore, the Phenomenological Method allows for a rich description of the students' perception of their feelings during the classes in school (Barraza \& Walford, 2002; Eldén, 2013).

Seventy-six students' drawings from two classes were collected in this study: 37 drawings from the class in which the students learned science through PT (the experimental group) and 39 drawings from the class in which the students learned science in the traditional approach (control group). Students from the two classes were asked to draw on one side of a sheet of A4 paper: "How do you feel during science class and explain what you drew in at least five sentences." The guideline on the other side of the page was: "Draw how you feel during non-science classes and explain what you drew in at least five sentences."

The students' drawings were analyzed by using the Qualitative Approach in two steps: 1) An Inductive Analysis was conducted for all the students' drawings in the first step and divided into tables (2 to 5). 2) The analyses were conducted according to four aspects: the cognitive aspect, the socio-behavioral aspect, the emotional aspect, and the value-based aspect. The analysis began with the numbering of the two classes' drawings (the experiment and the control groups) and by obtaining an initial impression of the students' drawings. This analysis was carried out on two levels: 1) The drawings were divided into four students' preferences as seen from the drawings: (a) Studying in the PT approach; (b) Studying in the traditional approach; (c) There is no preference for either of the approaches; (d) Not relevant (it is impossible to obtain an impression from the drawings and the texts what the students' preferences are). 2) Students' expressions were categorized deductively according to the four aspects (the cognitive aspect, the sociobehavioral aspect, the emotional aspect and the valuebased aspect) as found in the teachers' interviews. These expressions were counted and analyzed.

The quantitative deductive analysis of the drawings included a series of 12 - Chi-square goodness of fit tests. This series of tests is designed to examine the goodness of fit between the following variables:

Class type. This variable included two options: an experimental class in which PT was conducted and the control class in which PT was not conducted.

The facial expressions in the drawings. This variable included four options. A student with a happy face, a student with a sad face, a teacher with a happy face, a teacher with a sad face.

\section{Observation}

Five observations were conducted in classrooms where a science class through PT was taught in addition to the reflection meeting with teachers and students. All observations were recorded, transcribed, analyzed in an Inductive Approach, divided into categories as well as sub-categories. Student statements were added, ascribed to these categories and used as a reference.

\section{RESULTS}

This section's results are expected to answer two research questions that addressed the degree and adequacy of the teaching-learning goals of the Tzemach School, as formulated by the school staff and from students' point of view on PT.

This section addressed: a). the school staff's perceptions of the teaching-learning goals; b). the students' perception of teaching-learning goals expressed in PT classes and non-science classes; c); the degree and adequacy of the teaching-learning goals (school staff) and its expressions in the peer teaching class (students).

\section{A. The School Staff's Perceptions of the} Teaching-Learning Goals

The school staffs' interviews made it possible to examine the teaching-learning goals that emerge from the interviews with them. This examination was carried out in two steps.

Step 1. The teaching-learning goals according to aspects from the school staff's perception: This section presents the teaching-learning goals of the school staff according to four aspects: the cognitive aspect, the socio-behavioral aspect, the emotional aspect and the value-based aspect. The school staff's 
relation to the four aspects was not identical. Much attention was paid towards the cognitive aspect ( $46.5 \%$ of the total number of statements collected from all interviews with the school staff) that included categories such as creative thinking and critical thinking, while the socio-behavioral aspect (26.9\%) received less attention and included categories such as group collaboration and group gamification. The emotional aspect (17.6\%) included categories such as enjoyment of learning and sense of success. The valuebased aspect received minimal responsiveness (8.9\%). This aspect included categories such as man and the environment and leadership.

It seems that the difference in how the school staff related to the various aspects was a result of the encounter between theory and reality. Theoretically, the school is run within the Montessori spirit, which according to their agenda, is intended to promote social-behavioral values, even if it is at the expense of knowledge acquisition. Since those values are taken for granted by the school staff, they did not consideration them much attention. At the same time, the school principal addressed the issue of values in a well-defined and clear-cut way: "It's the sensitivity. Democracy... how you enter the classroom, how you manage it, how you treat your friend."

With regard to the cognitive aspect, which received the most attention in the interviews, this can perhaps be related to the day-to-day work of the school staff who were involved in preparing the class plans and the teaching itself. Yoav, a homeroom teacher, related to the question "What is the goal of the science curriculum?": "First it is necessary that the students become familiar with the various materials in nature... to know that each rock has a different composition, different matter, and different features... my goal, is that they recognize and know it all... "In addition, the teachers' task is to teach and therefore often refers to the cognitive aspect as teacher Simon said: "I am quite particular about having an orderly curriculum and learning strategy. "At the same time and naturally, the school staff encounters issues concerning the sociobehavioral aspect of PT. Yoav, a math teacher, sees the problem in having one sixth- grader teaching his friends from the same class: "...mature sixth graders who take the lead, still do not know how to allocate the roles according to the abilities of each student, or to be patient enough to let everyone express themselves properly..."

The same applies for the students' emotional aspect of as teacher Nurit described: ".../ mean, when we listen to them, they listen to us almost always. Really, this also happens in learning situations, too. "It is quite surprising that the school staff related very little to the emotional aspect because the credo of the school is based on this aspect. It is possible that the same goes for the value-based aspect. In addition, the emotional aspect is strongly ingrained in the school culture and therefore the school staff mentions it very little in the interviews. Another reason for this might be due to the interviews focusing on PT and not directly on these aspects. The school principal summarized the interaction of the teaching-learning goals according to the four aspects that are manifested in the daily life of the school staff: "...the basis for good learning, curiosity, initiative, creativity, leadership and so on is feeling good... not everyone feels good, even if they come from very good families. Lots of anxiety, lots of communication and relationship issues."

Step 2. Analysis of the operational goals from the school staff's perception: The teaching-learning operational goals that were extracted from the school staff's interviews were divided into the following seven categories:

A. Teaching Method. This category included goals of high-order thinking development as creative thinking and critical thinking, use of educational technology as use of presentations and computers, development of sorting skills, integration of multidisciplinary teaching, activation of diversity in teaching, use of research methods as observation and experiment, and integration of experiential learning in teaching.

B. Teaching Processes. These categories included goals of self-learning, collaborative learning is small groups, frontal teaching, preparation of the fellow teachers and providing feedback to students. The school staff emphasized the importance of collaborative work in small groups where intimacy was created that could not be created in a large classroom but also noted the importance of having all students in different areas of the classroom.

C. Teaching Environment. The school staff noted the importance of learning in nature, outside the classroom where students can connect to objects, plants and animals.

D. Acquired Knowledge. This category addressed acquired knowledge / scientific knowledge of the learning content, for example, rock characteristics and understanding the curriculum.

E. Self-Regulated Learning. This category includes goals such as human and environmental relations and leadership. The school staff addressed these value goals as part of educating students for personal and 
social development and becoming future adults in society.

F. Emotional Involvement in Learning. This category includes goals such as learning enjoyment and empowerment of students in developing responsibility and leadership.

To summarize, this section presented two divisions of teaching-learning goals as learned from the perspectives of the school staff. The first division addressed the four aspects of the goals (cognitive, social-behavioral, emotional and value-based) and emphasized the overreaching goals, and the second division emphasized the operative goals from which it is possible to understand how the school staff intends to achieve these goals according to each of the aspects (Table 1).

\section{B. Expressions of The Teaching-Learning in Peer Teaching Classes and Non-Science Classes from the Students' Point of View}

The meeting point between the goals set by the school staff and the way they expressed themselves to the students were examined if four ways.

1. Analyzing personal interviews with the fellow teachers who taught their classmates through peer teaching. The fellow teachers addressed a wide range of aspects in the personal interviews. Many of the statements referred to the characteristics of fellow teachers, such as leadership that includes values that should guide the fellow teachers in their work with the students. According to the interviews, the fellow teachers should have selfawareness and understand that they must help others. That is, fellow teachers indicated that they have a personal responsibility that they must demonstrate as part of their commitment to teach other students. At this point, students also addressed the leadership tools they acquired, which will serve them in their adult lives. In general, the fellow teachers felt positive about being chosen to teach their peers and that they could provide their peers guidance. Along with the characteristics of the role, the fellow teachers noted the benefits and challenges the role presented to them in PT as well as to the members of the group they taught.

The analysis of the interviews with the fellow teachers included a division of the statements into three aspects: cognitive, socio-behavioral and emotional. No reference was made to the value-based aspect in these interviews. Each of these aspects included a positive and negative reference to the fellow teachers' experience in leading the student groups in PT. In the cognitive aspect, the fellow teachers emphasized the importance of learning in small groups, which allows for a deeper understanding of the learning content, as Avia said: "When there are small groups you can learn the material better...." On the other hand, Aviv said: "Because perhaps the teacher can explain it [the study content] more comprehensibly."Aviv and Avia address the obstacle in which the fellow teacher did not explain the content as well as the teacher does. In addition, the fellow teachers noted points of this aspect such as their need to continually scrutinize themselves, to diversify teaching methods, to acquire group management tools, to learn the content before class, to be responsible for the content and its comprehension.

Regarding the socio-behavioral aspect, the fellow teachers related positively to the learning in small groups as Shiri, a fellow teacher, said: "It is more comfortable in small groups and there is more personal attention" or "...helpful for cooperation." Shiri mentioned social aspects such as cooperation and one-on-one attention that evolved from the PT whose method is based on small-group learning that enables the development of interpersonal relationships. Shabi, on the other hand, argued that in PT it often occurs that students do not listen and "sometimes there is all kinds of talking, and students wander around." Other issues that have come up regarding this aspect from interviews with fellow teachers are creating a social stigma about good students versus weak students, anxiety when exhibiting weakness in front of your friends or teaching your classmates. These issues can create social challenges and engrain the students' existing social status in the student-learning group.

Table 1. Details of the operational goals in each of the various aspects

\begin{tabular}{ll}
\hline Aspects & Operational goals that enable the achievement of the goals according to aspects \\
\hline Cognitive aspect & Teaching methods, teaching processes, acquired knowledge, teaching environment \\
Social- behavioral aspect & Teaching methods, teaching processes, teaching environment \\
Emotional aspect & Self-regulated learning, emotional involvement in learning \\
Value-based aspect & Acquired values \\
\hline
\end{tabular}


Regarding the emotional aspect, the fellow teachers indicated that they enjoy teaching their classmates. Shabi emphasized this point and said that he felt that the students in his group learn how to listen to him. Shiri, on the other hand, emphasized the awkwardness when the fellow teacher was younger than the rest of the leaning group, or her bad feeling when the students failed the test and then blamed her as the fellow teacher for their failure. In addition, the fellow teachers also addressed issues such as discrimination among students, which is expressed in an unbalanced relationship, a sense of boredom that the students projected in the learning group while the fellow teachers.

2. Analyzing of conversations of the focus groups in which conversation took place between the students and fellow teacher who participated in the peer teaching. The students' statements from seven mixed groups (students and fellow teachers) were analyzed according to the aspects created in the interviews with the school staff: the cognitive, socialbehavioral and emotional aspect. No reference was made to the value-based aspect in these focus groups. The discussions that developed in the focus groups addressed some aspects positively and some negatively. Regarding the cognitive aspect, the positive reflections included the ability of the fellow teachers to explain to the students that were studying through PT the content in their own "language", a language they understand. As stated in Focus Group 1: "... it is clearer when a child explains in a language we understand, in a way that we will understand..." In contrast, in Focus Group 2, there was also a negative reflection towards teaching through $\mathrm{PT}$, relating to the fact that teachers know how to teach better and explain the learning content more clearly. This negative comment connects to another negative reflection that arose in Focus Group 1, in which it was argued that the fellow teachers do not fully comprehend the content they are teaching. Other topics that were mentioned were the use of educational technology, integration of out-doorlearning, seriousness in learning, inaccurate teaching of content.

In the socio-behavioral aspect, the positive issue that arose in the Focus Group 1 is the team building created as a result of PT as noted by one of the students: "Usually, in the regular class, there is no team building, but with it, [PT] is much more than just team building". Focus Group 2 noted the fact that children do not behave well during PT as one of them said: "Sometimes there are kids in the group who take advantage of the fact that the teachers are not there." In addition, the students also mentioned issues such as wasting time, security of working in small groups, the possibility of new / in-depth acquaintances with new children, quarrels among students that may lead to exclusion and creating hierarchies in the peerlearning groups.

Regarding the emotional aspect, a student from Focus Group 1 claimed that it was easy for him to say things directly in the group itself: "because / feel like I can say anything / want. "A student from Focus Group 3 claimed that because the fellow teachers are the same age as the students they teach, this creates unease for those who have not been chosen to be the fellow teacher: "It makes the child feel less worthy than others". Other topics covered in the discussion included laughter during the group work, the personal attitude of the fellow teachers, a positive atmosphere, but on the other hand a sense of discomfort and impairing self-confidence and a general sense of inequality.

3. Analysis of observations in classes and in a reflective conversation between teachers and students who participated in peer teaching. The findings in this section were analyzed according to the aspects created in the interviews with the teachers: cognitive, social-behavioral and emotional aspect. No reference was made to the value-based aspect in these focus groups. Regarding the cognitive aspect, students indicated that they understood each other; it was possible to advance faster because there are fewer students in each group. Students also indicated that they encountered difficulties in PT. For example, there was not always enough time to work on all the assignments and learn all the material. They noted that sitting with friends caused them to concentrate less at times because group students instigated them to fool around. A student noted that a fellow teacher cannot always explain in depth and that the fellow teacher sometimes reads the texts "without explaining" because $s /$ he does not have enough knowledge as a teacher to explain the material well.

Regarding the socio-behavioral aspect, the students referred to the fact that girls and boys are together in the group, which is an addition aspect of social interaction, and that they experience a process of team building even though they indicated that there are also disagreements in the group.

In the emotional aspect, students felt more comfortable talking to a small group of students and asking for help than in the full classroom while on the other hand, students commented that the fellow 
teacher is actually a peer and a friend who ultimately makes decisions for the other group students - a situation that is not very pleasant.

4. Analysis of student's drawings of the experimental group and the control group. The analysis of the students' drawings, which included the experimental group and the control group, was intended to complete and strengthen the perception of the research partners' students towards the PT. The analysis of the drawings is conducted in several steps.

Step A - An Inductive Analysis of the Students' Drawings, Which Included Categories that Emerged from the Students' Drawings

1) Analysis of students' drawings from experimental science-peer teaching class. The drawings of the students who studied in a PT from the experimental class were divided into five categories according to the class work arrangement. It can be sensed from the students' drawings studying science in the experimental classroom using PT that there was a sense of joyfulness (Table 2). The students and fellow teachers benefited from the peer instruction and positive feedback was given by the teacher guiding the process. In addition, the group work reflected in the drawings does not characterize a regular class. Only some of the students are sitting around tables; teaching is conducted partly in the classroom and partly outside the classroom. At the same time, fellow teaching is similar to the traditional teaching that includes a teacher-centered approach. In addition, there is reference to differences and students' personal preferences in their way of learning such as sitting but not at a table.

2) Analysis of drawings of students' non-science experimental class \& non-peer teaching approach: The drawings of students who studied in the non-science experimental class were divided into categories according different types of classroom arrangements (Table 3).

In conclusion, it can be said that the students' drawings in the non-science experimental class express discomfort depicted in the sad faces and sleeping during the class. The typical teaching of the other disciplines in the experimental classroom takes place within the classroom where all students study together around tables. The instruction is based on the teacher-centered approach and the students copy from the board. The impression is that the students are an inseparable cluster and there is no reference to learning diversity and the individual needs of each student.
3) Analysis of students' drawings from control science class \& non-peer teaching approach. Drawings of students who studied in the control science class, using the non-PT approach were divided into categories according to the arrangement of the classwork (Table 4).

In conclusion, in this section there is no consensus among the students in the control class regarding their science classThe teachers seemed to be smiling but the students did not. In addition, students noted that the class was meaningful even though it was evident that science classes in the control group incorporated experiments performed by students or the teacher's demonstration. The science classes in the control group were held in the traditional approach in which the teacher was at the center in classes that were held outside.

4) Analysis of Drawings of Students from NonScience Control Class \& Non-Peer Teaching Approach.

Drawings of students who studied in non-science control classes and not through PT were divided according to the type of classroom arrangement (Table 5). In conclusion, it is evident that the teaching in a lesson of a different discipline in the control class is perceived as learning, where the teacher is at the center and the teaching is based on traditional teaching in which material is delivered by the teacher. This teaching is not perceived by the students as less interesting or less fun and this can be understood from the students' facial expressions and explanations. It is not clear what teachers feel about this way of teaching.

Step B - A Deductive Analysis of Students' Drawings, Which Included Categories Obtained from the Analysis of Interviews with Teachers.

This analysis included references to aspects found in interviews with teachers: the cognitive aspect, the social-behavioral aspect and the emotional aspect. In the experimental class, in the science classes that took place in PT, a picture was obtained in which the learning atmosphere is positive regarding a cognitive aspect. The students' drawings analyzed in step A indicated that regarding the social-behavioral aspect, there was cooperation between the students during the learning and regarding the emotional aspect, the joy of learning and enjoyment of the way of learning was apparent. The analysis of the drawings in the experimental class in other non-science classes, indicated the students' discomfort regarding the various aspects: For the cognitive aspect there was greater reference to negative aspects. For the socio- 
Table 2. Analysis of students' drawings from experimental science-peer learning class (includes the categories, representative drawing and description)

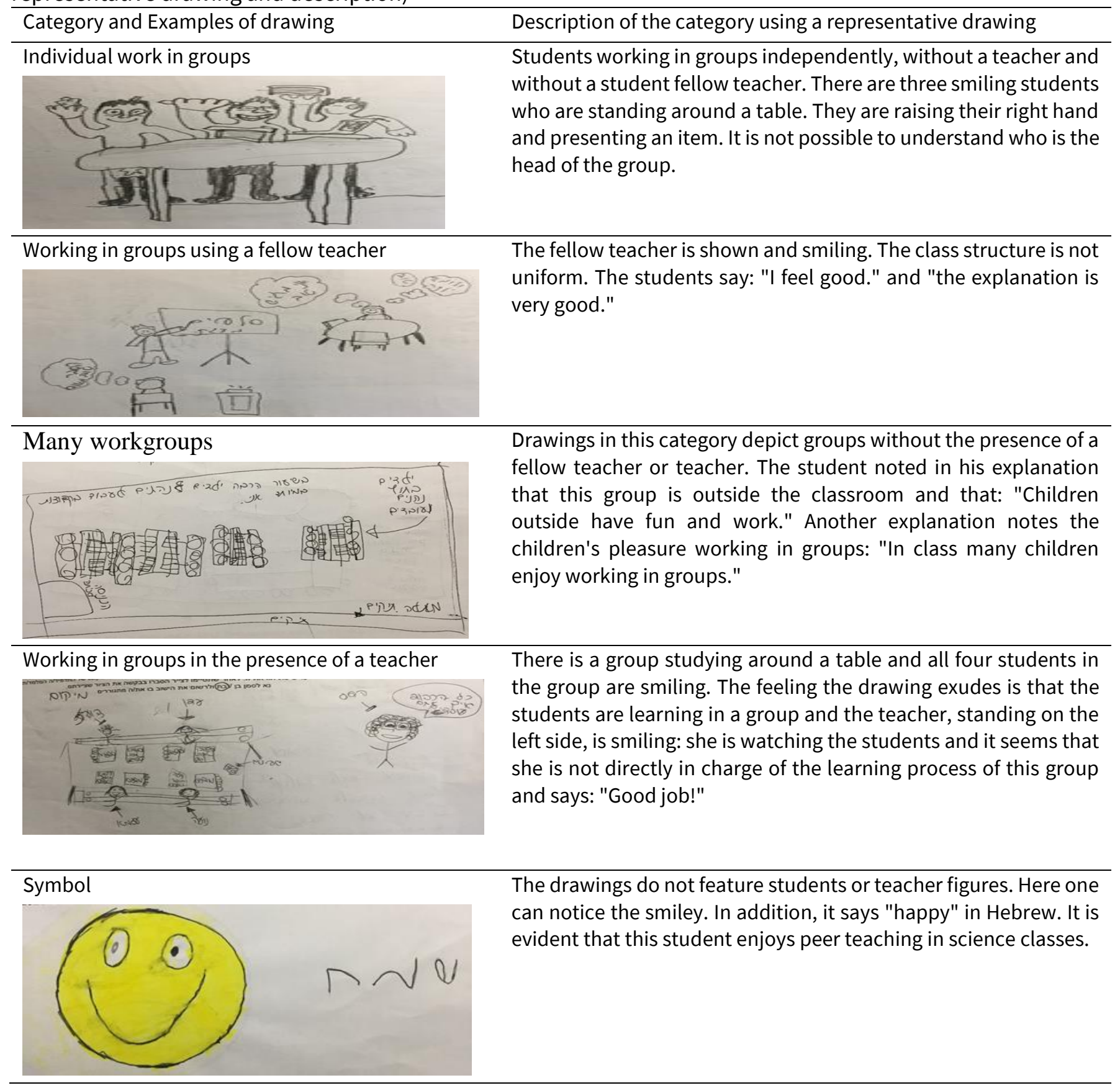

behavioral aspect there was almost no negative or positive attitude and for the emotional aspect, there was an ambivalent attitude towards learning in the different methods of PT, with a tendency towards negative feelings. The analysis of the drawings in the control class in science classes that were not taught in PT, indicated mixed feelings about learning. For the cognitive aspect, the centrality of the teacher in front of the students in the classroom was emphasized, and for the socio-behavioral aspect, reference to shared learning was low and positive. For the emotional aspect, there was limited reference. The analysis of the drawings in the control class in other lessons not taught in PT emphasizes that regarding the cognitive aspect, the students drew the teacher standing in the center in front of the class and regarding the sociobehavioral aspect there was little reference. Regarding the emotional aspect, mixed emotions appeared. The value aspect was not indicated in the students' drawings. 
Table 3. Analysis of students' drawings from non-science experimental class with non-peer learning approach (includes the categories, representative drawing and description)

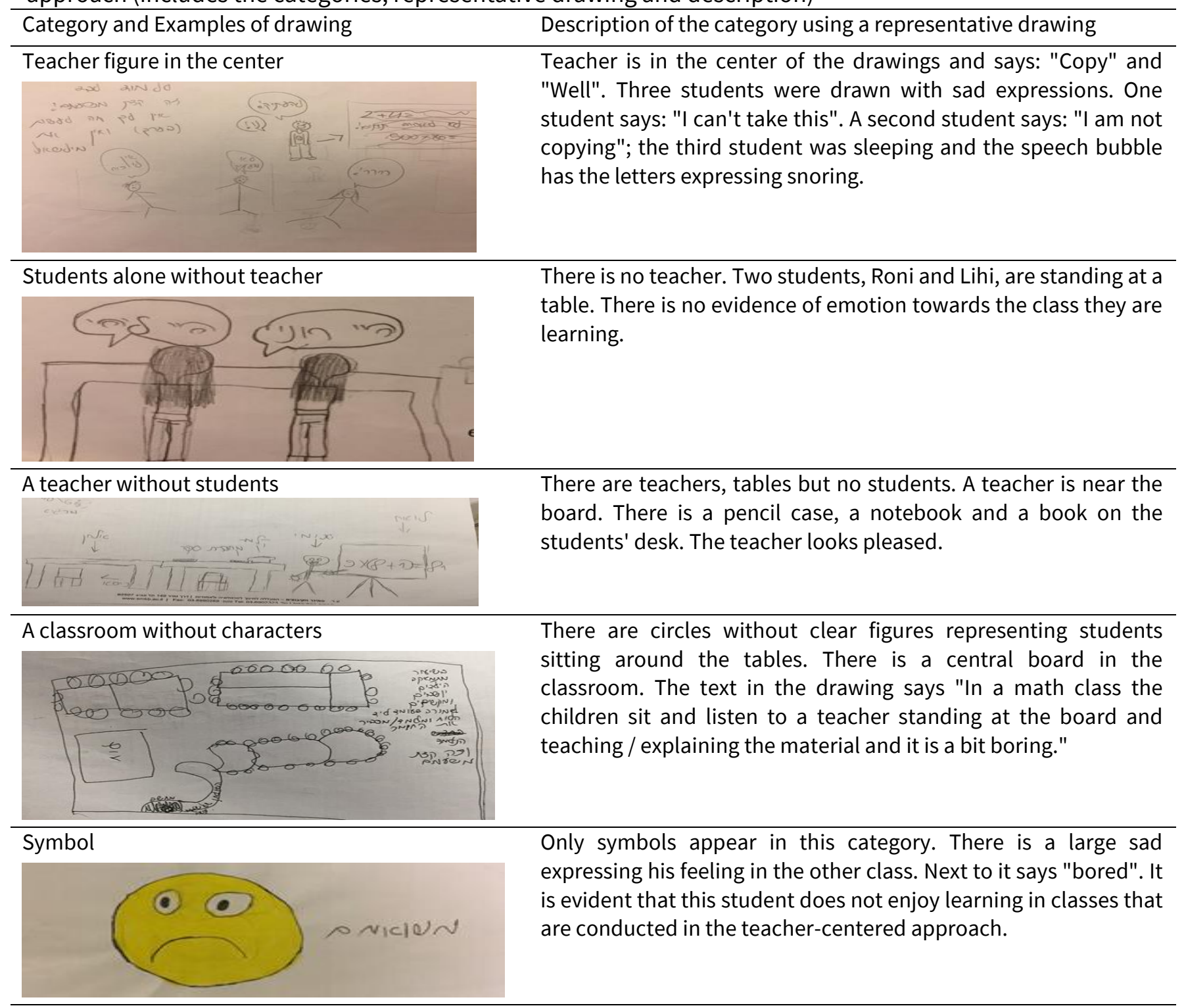

Step C - Quantitative Analysis According to the Class Type, the Facial Expressions in the Drawings and Another Scholastic Subject.

1. Chi-Square tests. A series of 12 chi-square tests were conducted to test the significant statistical differences between expected frequencies and observed frequencies. In this research between class type (experiment/control), the facial expressions in the drawings ("happy student" / "sad student", "happy teacher" / "sad teacher") and another scholastic subject (Science / Non-Science). The results of twelve Chi-square tests indicate that in four of these tests, significant statistical differences were found. In the drawings of the students who studied in the experimental class, where PT took place, more happystudent faces were depicted than sad faces compared to the drawings regarding non-science class $(p=$
0.011). Also, the students who studied in the experimental class drew more drawings of an alternative class structure than in the non-science class ( $p=0.0001)$. The students in the control class, where PT did not take place, also drew more of a different class structure that exists in the science classes compared to the non-science classes $(p=$ 0.002). However, the comparison of drawings of a different class structure between the two study populations indicates a significant statistical difference $(p=0.045)$, meaning that in the experimental class there were more drawings of a class with a different structure.

2. Descriptive analysis. All student explanations accompanying the drawings were analyzed in a content analysis. These explanations were divided into four aspects: Cognitive aspects that include 
Table 4. Analysis of students' drawings from control science class with non-peer learning approach (includes the categories, representative drawing and description)

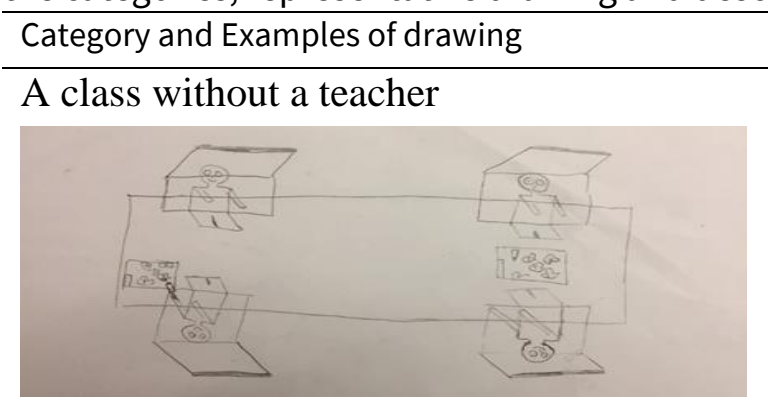

Description of the category using a representative drawing

A science class is being conducted around a table without the presence of the teacher. Rock kits are on the table. The smiles on the students' faces indicate that they are satisfied.
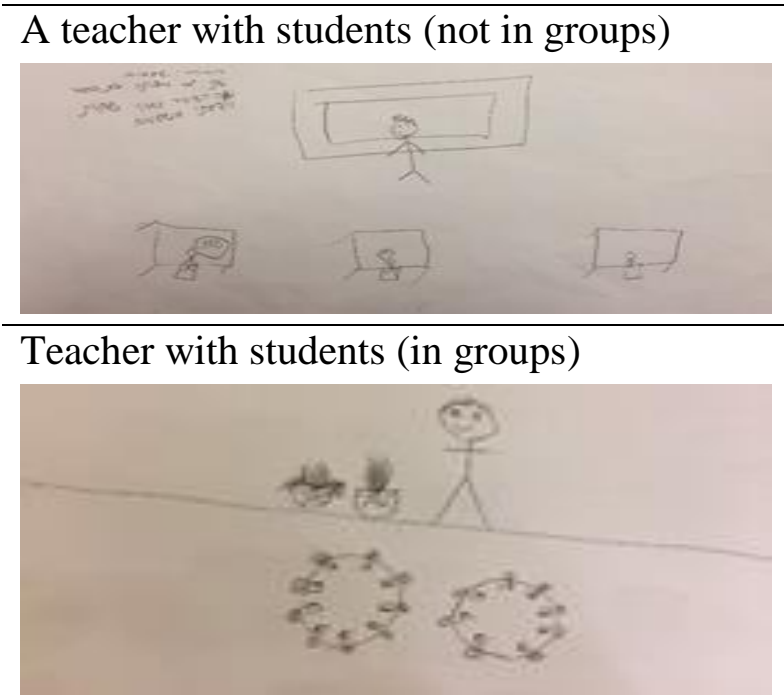

A teacher is standing at the board and in front of him three students at their desks that are far apart from each other. The teacher is smiling but in the text on the right it says: "I hate this class and I think is boring." In this text, the difference between the teacher's feelings and the students' feelings is evident.
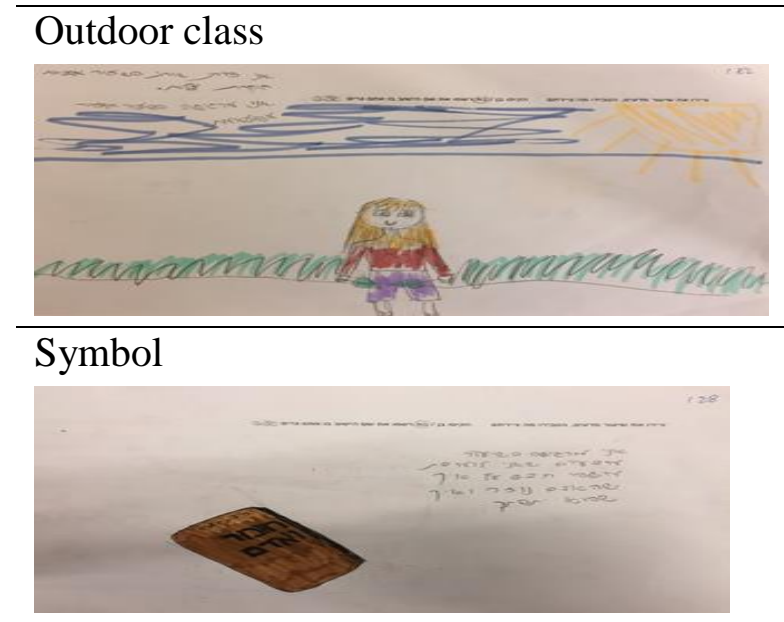

The teacher is smiling and in front of him are two round tables with students. Round tables can imply non-traditional learning. The teacher is standing by the board and next to him are two experimental jars.

expressions such as: asking questions and learning outdoors. Explanations in the socio-behavioral aspect that include expressions such as: part of a group and freedom. Emotional aspects that include expressions such as: enjoyment and happiness (Figure 2). Explanations pertaining to an additional aspect that include expressions such as "special" have not been added to Figure 2.

Figure 2 emphasizes that in the experimental class there were fewer references to the cognitive aspect compared to the control class and more references to the socio-behavioral aspect, while in the control class there were more references for the emotional aspect compared to the experimental class.

Explanatory expressions in drawings of science classes (PT approach) and non-science classes (not taught in this approach) in the experimental class were divided into expressions that support PT, such as 'laughs' and 'learns' and expressions that do not support PT, such as 'not focused'. It was found that the percentage of expressions that support PT in science classes was high in each of the aspects in the experimental class: the cognitive aspect, the sociobehavioral aspect, and the emotional aspect. On the other hand, it was found that the percentage of 
Table 5. Analysis of student' drawings from non-science control class with non-peer learning approach (includes the categories, representative drawing and description)

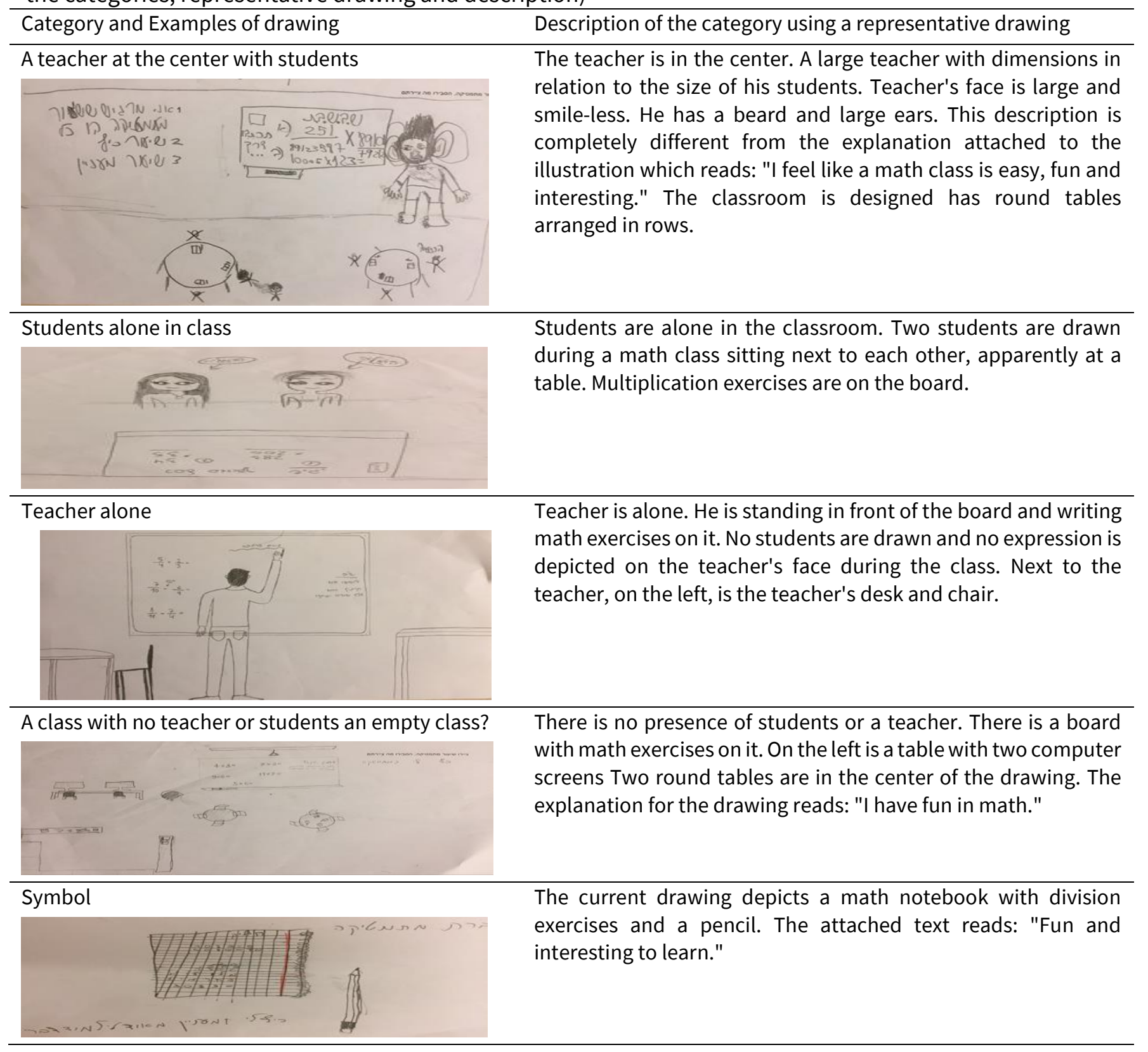

expressions that did not support PT in non-science classes was high for each of these aspects (Table 6 and Figure 3). Science classes and non-science classes were also held in the control class in a non-PT approach. It was found that the percentage of expressions in the socio-behavioral aspect and the emotional aspect were higher in non-science classes.

In contrast, the percentage of expressions that support science classes other tha $\mathrm{n}$ the PT approach was higher in the cognitive aspect. In science classes, the percentage of expressions in the socio-behavioral aspect and in the emotional aspect is higher compared to the non-science classes. In addition, the cognitive aspect showed a higher percentage of aspects that did not support non-science class as compared to the percentage of the number of expressions that did not support this aspect in the science class (Table 7 and Figure 4). In conclusion, there is a clear preference of students in the experimental class to study science classes in a PT approach in each of the aspects examined: cognitive, social-behavioral and emotional, compared to the non-science class where PT does not take place. However, no consistent picture was found in the control class.

The Degree and Manner of Alignment Between Teaching-Learning Goals (School Staff) and Expressions in Classes (Students)

This part is an integration of Section A, which dealt with the goals of teaching-learning from the school 


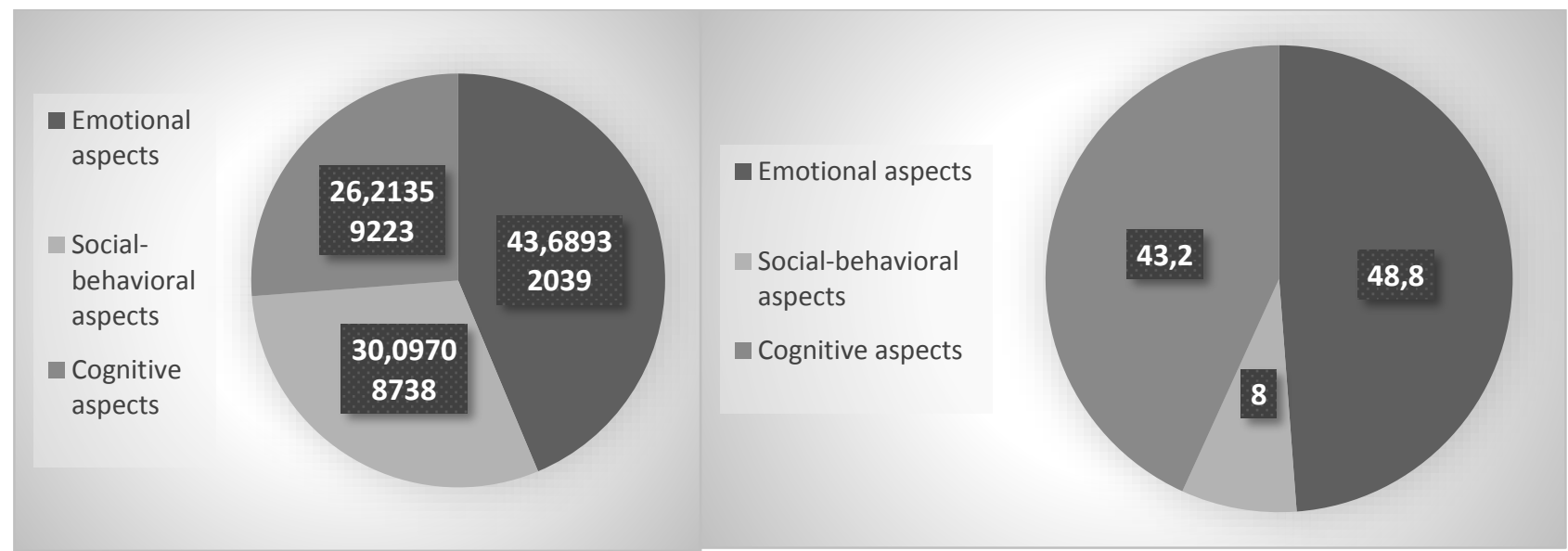

Figure 2. Percentage of statements in each of the categories: cognitive, social-behavioral and emotional (left: the experimental class, right: the control class)

Table 6. Percentage of supportive expressions and percentage of expressions that do not support the different classes in the experimental class

\begin{tabular}{|c|c|c|c|c|}
\hline & \multicolumn{2}{|c|}{ Science classes with peer teaching approach } & \multirow{2}{*}{$\begin{array}{l}\text { Another scholastic } \\
\text { teaching approach } \\
\text { Supportive } \\
\text { expressions (\%) }\end{array}$} & \multirow{2}{*}{$\begin{array}{l}\text { subject without peer } \\
\text { Non-supportive } \\
\text { expressions (\%) }\end{array}$} \\
\hline & $\begin{array}{l}\text { Supportive } \\
\text { expressions (\%) }\end{array}$ & $\begin{array}{l}\text { Non-supportive } \\
\text { expressions (\%) }\end{array}$ & & \\
\hline $\begin{array}{l}\text { Cognitive } \\
\text { aspect }\end{array}$ & 63.0 & 7.4 & 7.4 & 18.5 \\
\hline $\begin{array}{l}\text { Social-behavioral } \\
\text { aspect }\end{array}$ & 38.7 & 12.9 & 12.9 & 25.8 \\
\hline Affective aspect & 35.6 & 8.9 & 8.9 & 46.7 \\
\hline
\end{tabular}

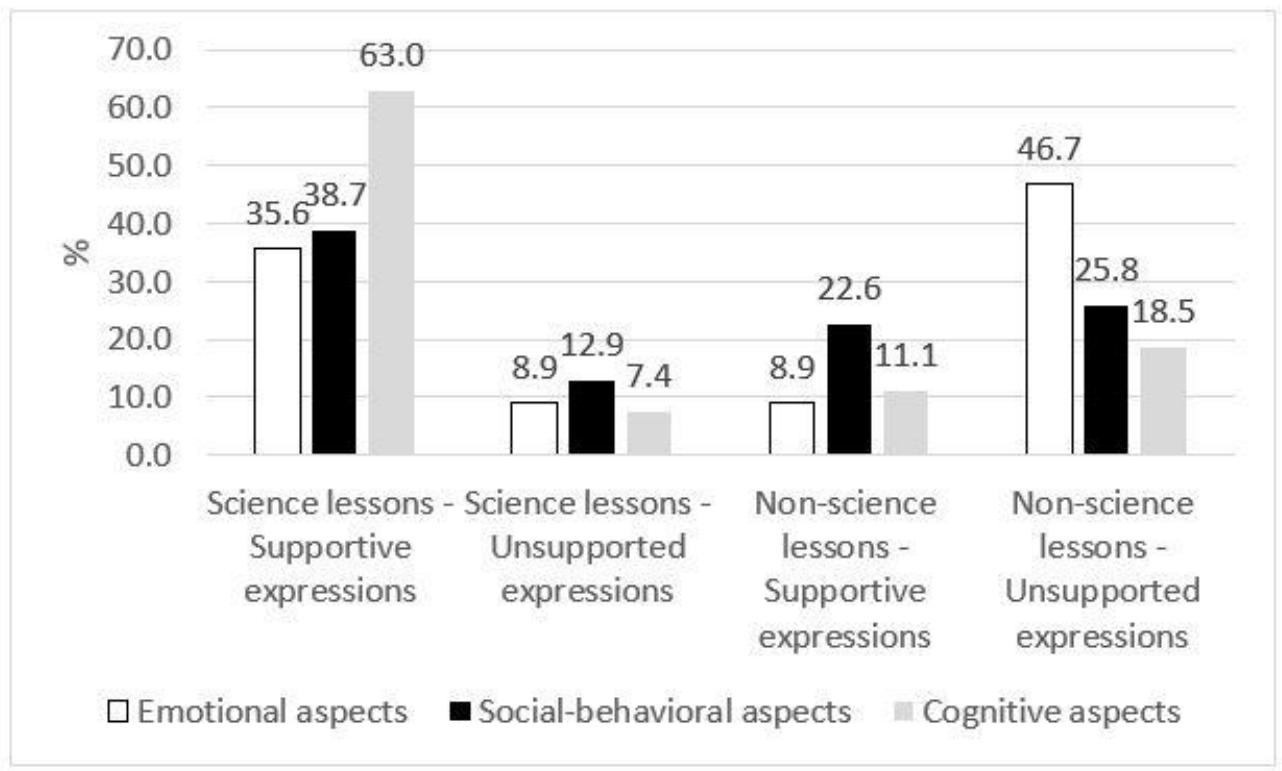

Figure 3. Experimental class: distribution (\%) of supportive expressions and non-supportive expressions in science classes taught in a peer-teaching approach compared to non-science classes which peer-teaching did not take place

staff's perception, with Section B, which dealt with the students' perception towards their experience in actual PT. That is, this section answers the second research question: How are the teaching-learning goals formulated by the school staff at Tzemach 
Table 7. Percentage of statements that support and do not support each of the categories in the control class

\begin{tabular}{|c|c|c|c|c|}
\hline & \multicolumn{2}{|c|}{ Science class with peer teaching approach } & \multirow{2}{*}{$\begin{array}{l}\text { Another scholastic subject } \\
\text { approach } \\
\text { Supportive expressions (\%) }\end{array}$} & \multirow{2}{*}{$\begin{array}{l}\text { without peer teaching } \\
\text { Non-supportive } \\
\text { expressions (\%) }\end{array}$} \\
\hline & $\begin{array}{l}\text { Supportive } \\
\text { expressions (\%) }\end{array}$ & $\begin{array}{l}\text { Non-supportive } \\
\text { expressions (\%) }\end{array}$ & & \\
\hline $\begin{array}{l}\text { Cognitive } \\
\text { aspects }\end{array}$ & 42.6 & 7.4 & 7.4 & 16.7 \\
\hline $\begin{array}{l}\text { Social- } \\
\text { behavioral } \\
\text { aspects }\end{array}$ & 10.0 & 40.0 & 40.0 & 10.0 \\
\hline Affective aspects & 27.9 & 24.6 & 24.6 & 9.8 \\
\hline
\end{tabular}

School in science classes taught through peerteaching, from the students' perception?

In general, it is conceivable that there is a correspondence in all aspects in the goals set by the school staff and the students' experience of PT in the experimental class (Figure 5). For example, the percentage of goals formulated regarding the cognitive aspect was the highest compared to the other aspects.

To check whether such a correspondence indeed exists, the students' expressions that referred to their experience were classified as positive expressions towards the experience and negative expressions. Comparing only the positive expressions versus the teaching-learning goals of the school staff revealed a slightly different picture. That is, the socio-behavioral aspect received the most positive response from students in their experience in science classes in PT and not the cognitive aspect (Figure 6).

However, the picture changes completely when comparing the teaching-learning goals of the school staff with the non-supportive expressions of the students towards their experience in PT (Figure 7).

Figure 6 shows that students relate negatively to their experience in the cognitive aspect of PT in science classes in the experimental classroom. For the other aspects, except the value-based aspect, there is negative reference, but less.

\section{DISCUSSION and CONCLUSIONS}

This research focuses on the PT in science education in an elementary school among students from fourth to sixth grades. However, literature rarely reports on studies that have examined PT in science subjects and elementary schools. There are diverse

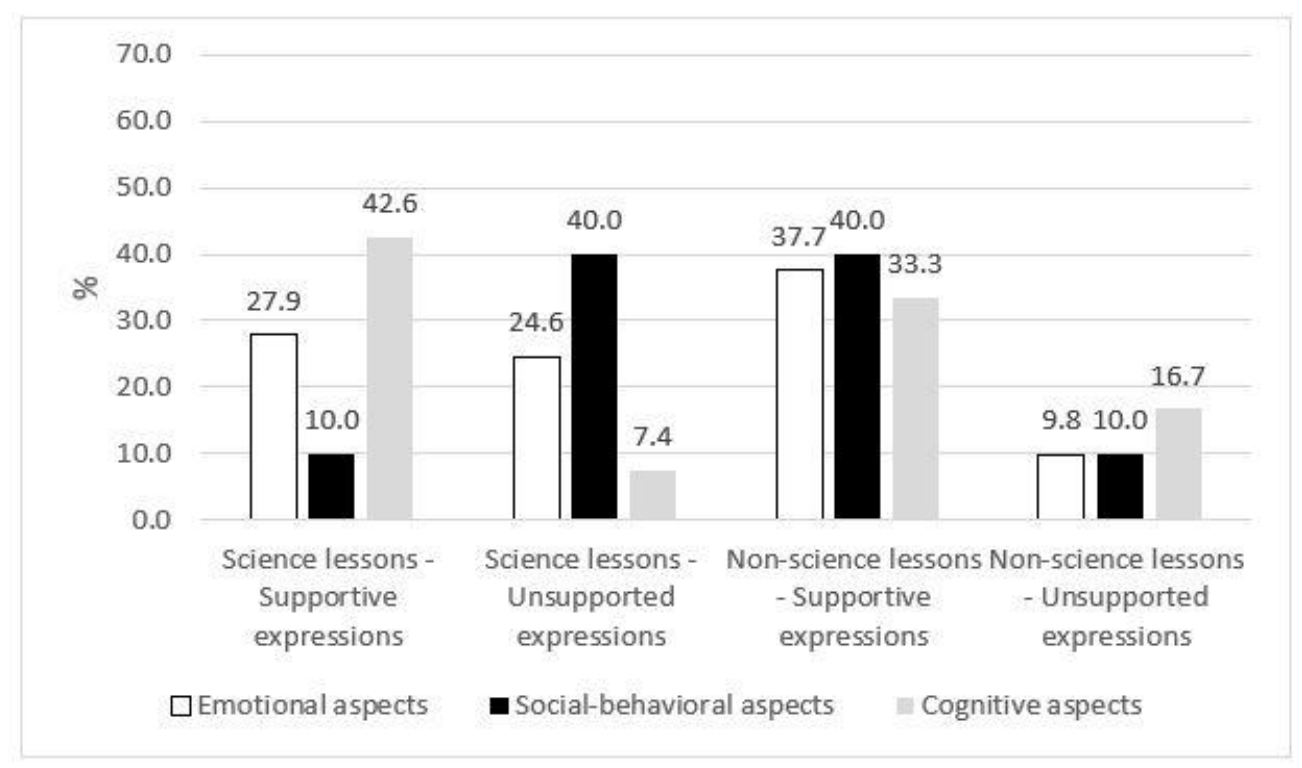

Figure 4. Distribution (\%) of supportive expressions and non-supportive expressions in the control class in which peer teaching approach was not adopted - comparison between a science classes and nonscience classes 
models and studies that address this pedagogy of teaching based on the principles of the social learning theory that allows students to acquire tools for future use while engaging in social interaction (Vygotskii, 1978), which has a major impact on students' cognitive thinking and SEL (Campolo et al., 2013). The introduction to this article described the benefits and challenges facing the educational staffs and the fellow teacher of such learning. Awareness of such and other benefits and challenges can promote the planning and execution of educational teams that plan to implement this approach. Surprisingly, sometimes, benefits of the perception of the school staff can be a challenge for the students, and sometimes a challenge of the perception of the school staff can serve as an advantage or a weakness for the students, as found in this study. Examining the meeting point between the perception of the school staff and the students' perception is important to promote learning through this approach and can also indicate components of the

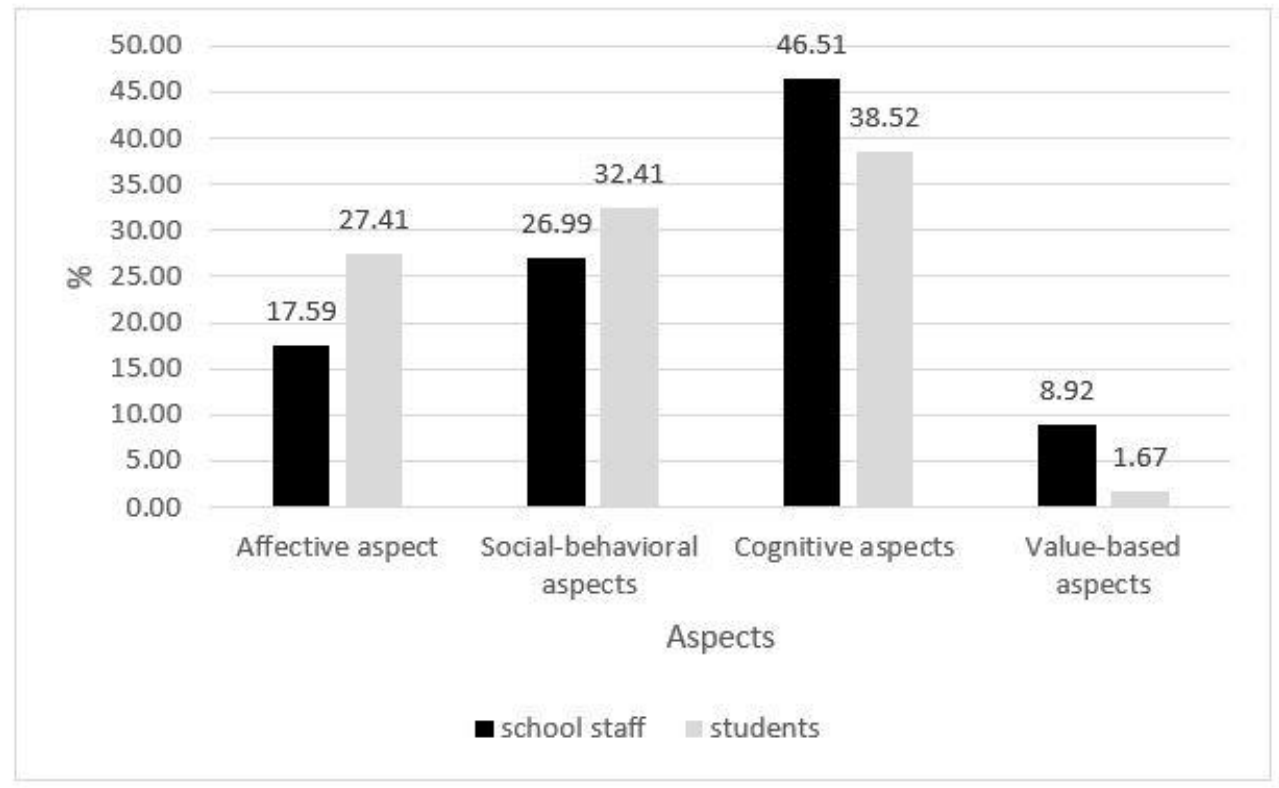

Figure 5. Comparison of the application of the goals set by the school staff in relation to the activities performed by the students in the experimental class from students' perception

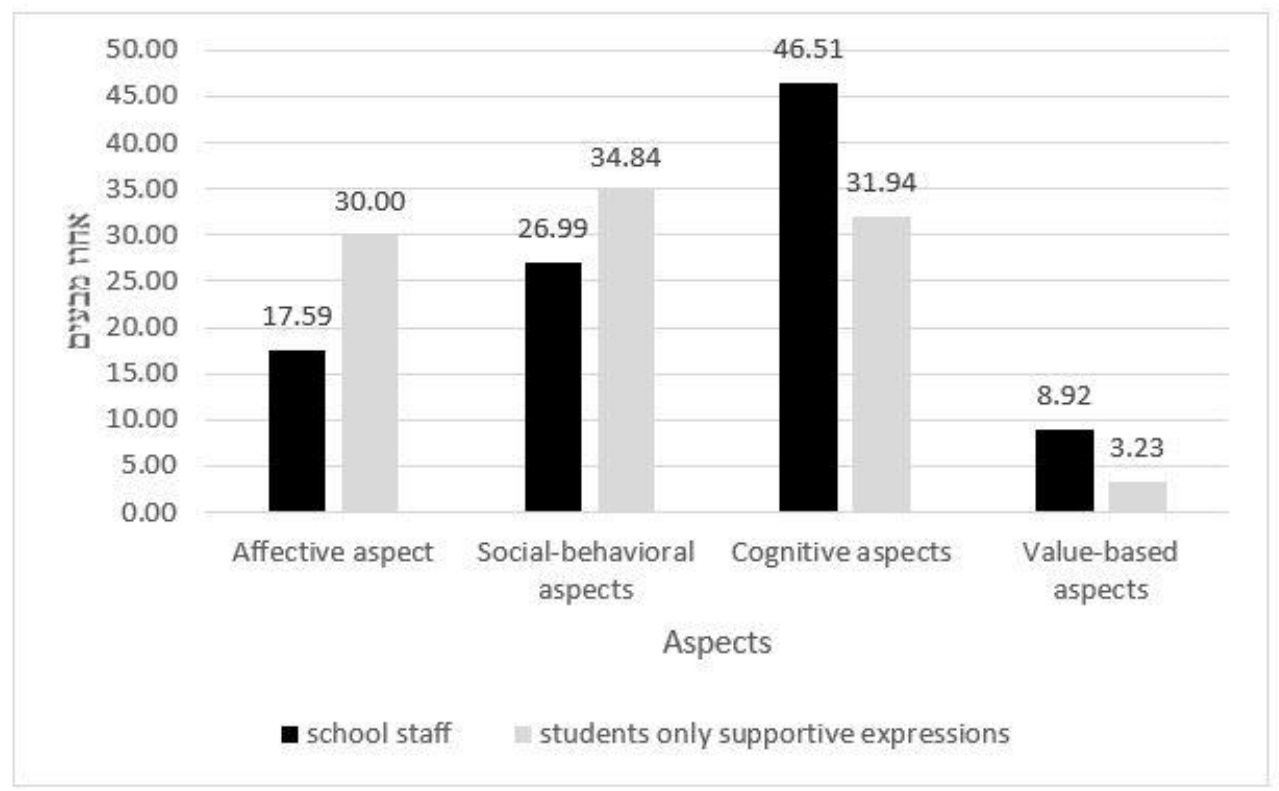

Figure 6. Comparison of the implementation of the goals set by the school staff versus the activities performed by the students in the experimental class from their perspective - supportive expressions only 


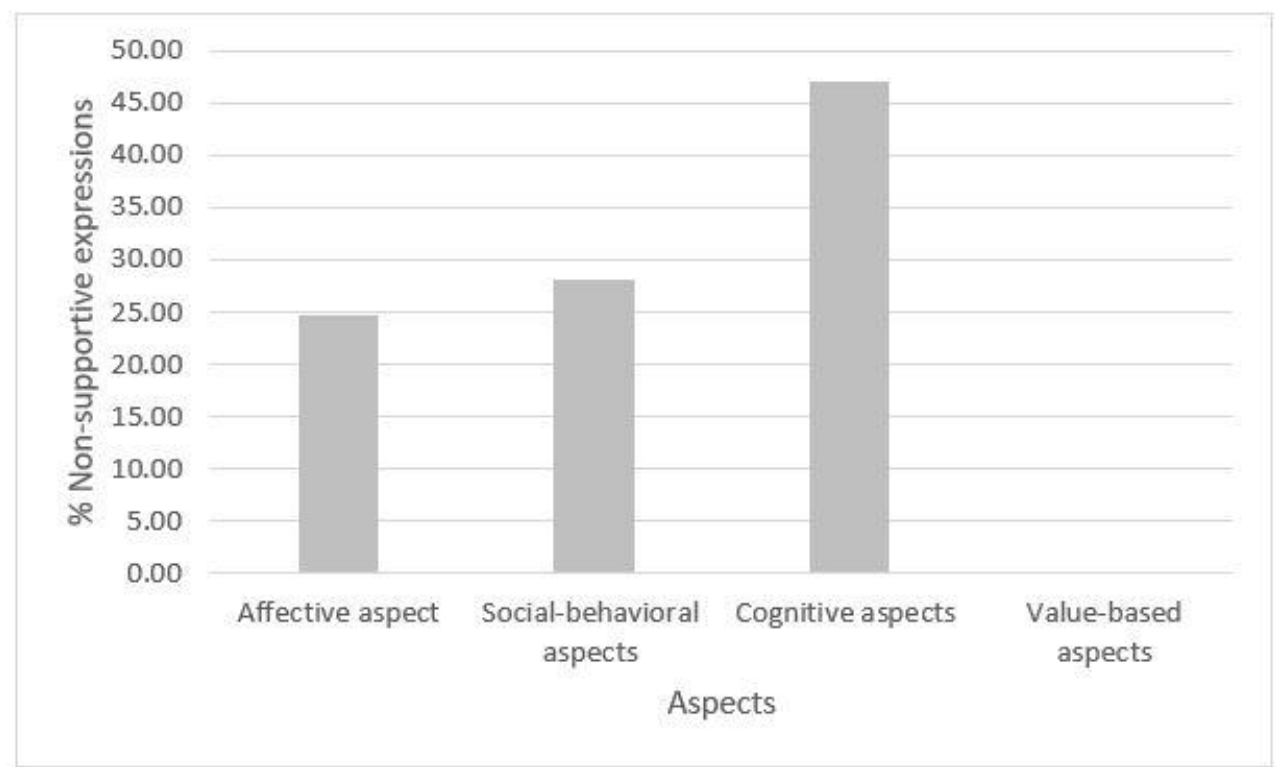

Figure 7. Students' non-supportive expressions towards their experience in peer teaching in science classes in the experimental classroom

approach that should be maintained or changed. In fact, our study examined whether there is a correspondence between the teaching-learning goals as raised by the school staff at Tzemach School and how these goals are reflected in the perception of students learning in PT. In light of this, and of the findings, the discussion focuses on two issues.

\section{A. Perceptual Gap in Relation to Peer-Teaching Implementation between the School Staff and the Students}

The findings show that there is a gap in the practice of implementation of PT between the school staff and the students in all aspects. This gap is expressed in the stated teaching-learning goals of the school staff and their implementation in the field. The school staff has mainly emphasized teaching-learning goals in the cognitive aspect, such as developing higher-order thinking skills and problem-solving. In contrast, students expressed in their own critical view in a variety of ways that was hardly voiced among teachers. This voice is exceptional due to their young age; it is crucial for adults heed their voice in order to learn from it and in turn, encourage them to learn (Cutter-Mackenzie \& Rousell, 2018). However, students noted the benefits of PT in acquiring knowledge, but at the same time, they did not spare criticism related to this aspect. The students stated more than once that the fellow teacher is better equipped than the class teacher to explain the material learned in their "own language" and at eye level. This deduction is also known from the literature (Boud \& Alison, 2007). As shown in Figure 6, most of the reference in the application of PT regarding the cognitive aspect was negative and increased the complexity of acquiring content knowledge (Lockspeiser et al., 2008). Elementary school students argued that PT was not effective in acquiring well-founded, in-depth knowledge in the teaching unit they studied in the sciences and that fellow teachers did not know the material well enough (Campolo et al., 2013; Stigmar, 2016). Moreover, the fellow teachers' explanation was not always understood; they did not know how to answer questions and their pedagogy was sometimes uninteresting. The analysis of the drawings supported this critique; students from the experimental class who studied with the PT drew the fellow teachers as teachers at the center of the class or showing that they had adopted a teacher-centered approach. It seems that the focus of the school staff on cognitive goals probably also affected the fellow teachers. The teacher-centered approach was a source of emulation for the fellow teachers; some the fellow teachers taught the content by reading chapters in the textbook and by presenting on the laptop. Thus, the idea of PT where students learn from each other cooperatively on equal terms has missed the point of social learning. Our findings contradict the literature (Olle \& Durning, 2007), which argues that PT is a substitute for the teacher-centered approach where students are able to teach content to their peers in place of the teacher (Lockspeiser et al., 2008). This may be due to different research populations since the PT population mostly takes place with higher-education students (Mckenna 
\& French, 2011; Pålsson et al., 2017) whereas, this study involves elementary-school students.

Another gap was found between the formulation of the teaching-learning goals of the school staff regarding the socio-behavioral aspect and their application in the class as expressed by the students. This gap was first manifested by the fact that students addressed this aspect more than the school staff. The fellow teachers emphasized the socio-behavioral aspect rather than the cognitive aspect as they are a selected group with an esprit de corps that has been fostered by the science teacher and the school staff and which is noticed by their peers. Similar to the cognitive aspect, regarding this aspect the students' attitude towards PT is ambivalent as well. The positive side included addressing issues such as collaboration, mutual help, forming a unified social structure and addressing social learning, which is also recognized in the literature (Olle \& Durning, 2007). The analysis of the students' drawings in the experimental classroom indicated a positive point of view regarding the sociobehavioral aspect. On the other hand, students noted the challenges in learning, such as disagreements and arguments among them.

From an emotional point of view, students related to PT much more than the school staff. It can be said that students had a positive emotional experience from PT, but at the same time emphasized the negative aspects. The positive emotional aspect is expressed, among other things, in the students' attitude towards the common language they have with the fellow teachers of their peers and their classmates, which contributed towards a pleasant feeling while learning. Students positively addressed the patience and inclusion of the fellow teachers' repetition of the explanations related to the curriculum and the integration of interesting experiences in the group. The drawings from the experimental class showed smiling faces of the students, which projected a sense of enjoyment. The fellow teachers emphasized their personal responsibility for teaching positively. Some students felt less privileged because they were not chosen to be fellow teachers, which caused them to feel less worthy and appreciated. Students also noted that fellow teachers would behave condescendingly towards other students on occasion, i.e. their peers, deciding what they should or should not do.

The students and the school staff paid very little attention to the value-based aspect compared to the other aspects. The school staff addressed this more than the students. The lack of attention by the school staff was surprising, since the impression of Tzemach
School's vision was that values are first and foremost in the teaching-learning school. The students, in some measure, addressed the values that the administration mentioned. It may not be a process of naming the values that the school staff is interested in instilling in students and that is part of the covert curriculum (Alsubaie, 2015). At the same time, there was correspondence in the value aspect between the teaching-learning goals mentioned by the school staff and their application in the field as noted by the students on the subject of the interaction between Man and the environment. A similar correspondence was also found between the goals of the school staff and the implementation of these goals in value-based aspects, such as helping others, behaving according to the values of democracy and developing leadership. The literature reports that in educational programs it is vital to declare explicitly the learning goals to the students who are involved in it as well. These goals should not be the sole property of teachers. Students who are made aware of learning goals can improve their performance (Vedder-Weiss \& Fortus, 2011).

In conclusion, it was found that there is a partial correspondence between the goals of the school staff and the implementation of these goals in the field from the students' perspective. Students demonstrated critical thinking toward PT. Moreover, it can be seen that students emphasized the benefits of this approach, but the challenges and difficulties they anticipated in interviews, focus groups, and drawings lead to a rethinking of the PT model as it is applied in a science class at Tzemach School. It is possible that this model requires a change that will preserve the benefits that the students mentioned, and at the same time attempt to address the challenges that the students anticipated. Such a model is described in the next section.

\section{B. An Extended Model for Implementing Peer Teaching}

It is evident that Tzemach School has not provided enough attention to the transference of responsibility of the fellow teacher for teaching the content to his/her peers, and was remiss in examining the level of knowledge of the students, vis-a-vis the contents they were taught. At the same time, the experience of PT in Tzemach School did not reach levels of uncontrolled behavior experience as reported by Mennim (2017). Students recommended that the science teacher be more involved at three time points throughout the PT session: A. Before the class - the teacher will support the fellow teacher and clarify the content being taught. 
This is in addition to what has already been done by the science teacher in advance: sending the material a week before and meeting prior to the class itself. Moreover, the students recommended that at the beginning of each class the teacher make a brief introduction to all students in which $\mathrm{s} / \mathrm{h}$ will guide the learning process and highlight the content. B. During the classes - the teacher will accompany the learning groups during the class more closely and thus, will assist the fellow teacher in his/her explanations if necessary. The teacher will also make sure that the students in the group have understood the content being taught in a scientifically acceptable way. C. At the end of the class - the science teacher will summarize the class and each student will complete the personal summary that he must write in his/her notebook at the end of the group work.

The students in this study referred, as stated, mainly to the cognitive aspect. At the same time, it can be concluded that the school staff and students faced challenges in PT regarding all four aspects: cognitive, social-behavioral, emotional, and value-based. Therefore, a model (desired model) is proposed that combines the current PT process (the existing model) and also addresses the challenges that have emerged in this study in all aspects (Figure 8). The model is similar to a Gantt board that includes a score of four categories vertically (bottom to top) and includes: date (when to apply?), stages (stages of application), common model (the model used in Tzemach School) and a desired model (developed based on the findings of this study). Horizontally at the bottom of the model are details of the implementation dates and eight stages of the PT process: Steps 1-4 take place before they start in class. Steps 5-7 take place during the class in which PT takes place. Steps 8-9 are executed at the end of the study unit. The model represents the application of the various aspects with the help of squares depicting the four aspects as well as three circles depicting different actions in the PT process that have emerged from the study.

\section{Recommended Elements Added in the Desired Model}

The Four Aspects. The desired model emphasizes the need to address all four aspects that emerged in this study that should be addressed throughout the PT process, and emphasizes the repetitiveness in the verbal representation of the various aspects in light of the existing gap between the representations of the various aspects in this study.

The Steps. In the desired model, a number of stages were added:

Step 3-Teacher-fellow teachers meeting: Teacher should check that the fellow teacher is ready to teach. This stage addresses claims that at times the fellow teachers do not prepare themselves properly for the class and do not study the material that is sent to them about a week before the class and is only carried out two days before the class.

Step 7 -Class summary by the science teacher: The science teacher should summarize the lesson for all

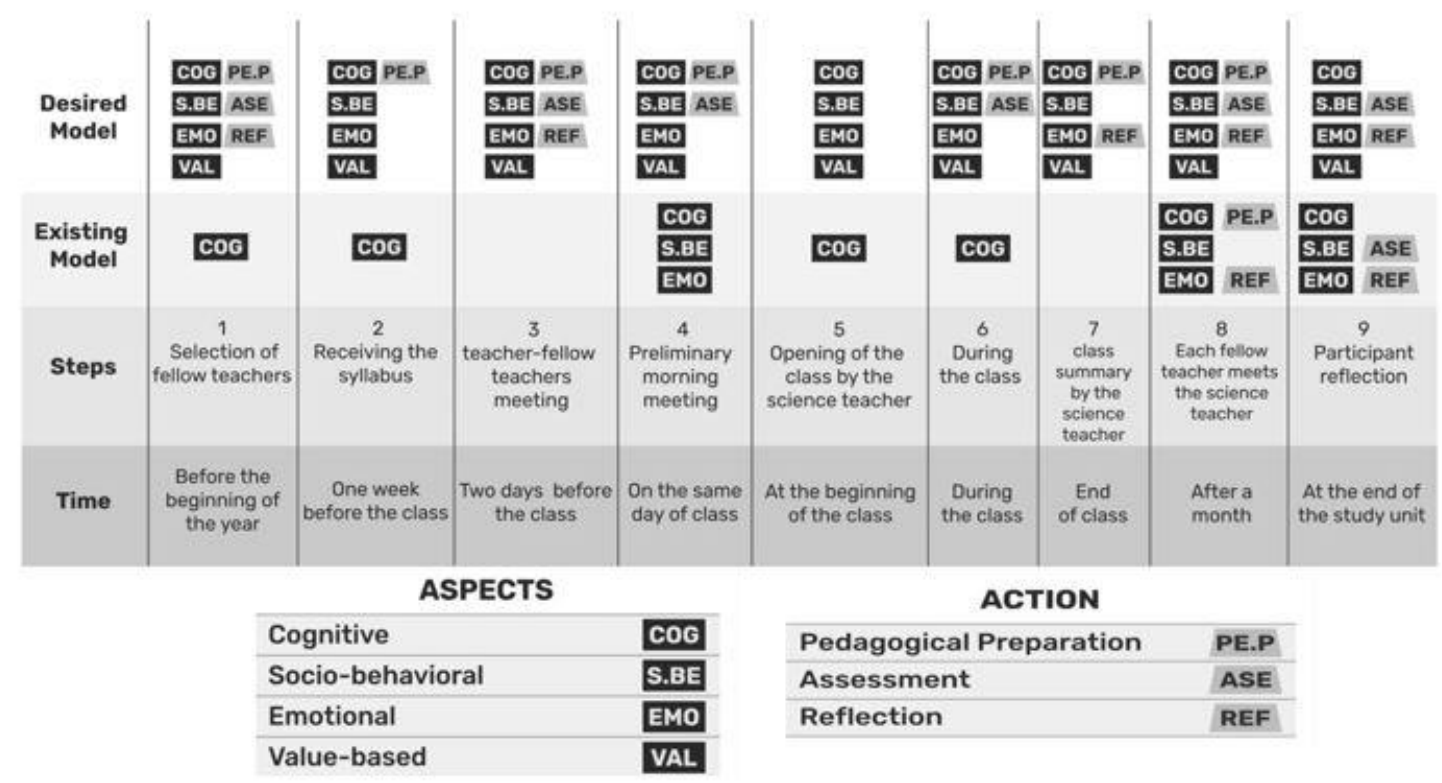

Figure 8. Comparison between the model found in Tzemach School in peer teaching and the desired model. 
students and not leave the summary to fellow teachers.

Step 8 - Each fellow teacher meets the science teacher: The teacher's feedback meeting with the fellow teachers takes place at the end of each class instead of once a month.

Actions. The desired model recommends combining three actions during PT.

Pedagogical preparation. A teacher's training takes years and also includes his/her experience gained during this work (Şen, 2010). In addition, the capabilities and maturity of the teacher are a very important part of his/her skills. There is no expectation that a fellow teacher will be able to teach as a teacher does. Therefore, it is recommended that the teacher leading the PT provide the fellow teachers with practical tools for diverse teaching methods of the content.

Assessment. In the desired model, it is recommended that assessment be carried out at different points in time in the learning process and not only at the end, and that an alternative assessment be combined with the traditional assessment in the existing model. Such an assessment will also serve in shaping the PT process and focus on points that need to be strengthened and improved.

Reflection. In addition to the reflection that takes place at the end of the existing process, the model offers additional points for reflection: at the end of Step 1 where the initial training of the fellow teachers takes place, at the end of Step 3, and a short class recap at the end of each class.

In conclusion, implementing PT does not add up to a procedural decision. It requires systematic organization of the school in changing the perception of the teacher's position and the perception of the students' method of learning. The desired model can provide a framework for enabling PT in individual teaching units, on various study topics in addition to science.

\section{Recommendations for Using the Model}

Adapting PT requires careful planning that takes into account the learning environment, its goals, curriculum, partners in the process, assistive techniques, frequency of meetings throughout the process, materials available to partners, preparation of fellow teachers and assistants, process monitoring, student evaluation and process feedback. The present model considers all of these factors and suggests addressing the following recommendations as well:
1) It is advisable to address each of these aspects and activities when implementing the model. Addressing these aspects will help reduce the gap between the stated goals and their implementation in the classroom in PT.

2) It is a linear model designed to narrow the gap between the goals of the school staff and the application of these goals in the classroom. Therefore, it is recommended to enact all the steps in the order shown in the model.

3) It is recommended to expose the fellow teachers and students to the model and use the terms that appear in it and thus create a common and professional language.

4) It is recommended to begin training the fellow teachers about six months in advance to support them and detect difficulties in advance.

5) The PT process is more time consuming than traditional learning. It is therefore advisable to allocate the appropriate amount of time for this process.

We would like to emphasis that this research has had significant implementation during the COVID-19 crises. In the period during the pandemic in which children around the world were subjected to social isolation and distancing from their teachers and peers, it is essential to adopt a PT approach that addresses the adaptation of the existing teaching system to the 21 st century. The combination of acquiring knowledge while providing a social emotional response is not age dependent. All school students in the world subjected to COVID-19 restrictions need to address and develop social and emotional learning abilities. Specifically, for this study, it was found that even elementary-school children can learn in a PT approach while developing emotional social abilities in learning.

\section{CONTRIBUTION and LIMITATIONS}

The research has both a practical contribution and a theoretical contribution. On the practical side, Tzemach School is attempting to promote an agenda that will include not only the cognitive aspect but also other aspects of teaching. They try to emphasize emotional, social-behavioral and value-based aspects. Promoting this agenda requires a great deal from of the school staff in order to put this agenda into practice. The present study makes it possible to examine whether the agenda of the school staff is indeed being implemented in practice. This is in light of the familiar fact that agendas, important as they are, remain at a declarative level only and fail to reach realization in the field. Therefore, examining the 
correspondence between the students' words and the goals formulated by the school staff will enable the school staff at Tzemach School to optimally implement the educational agenda in which they believe. Another practical contribution of the study is that it can help understand the benefits, barriers, and challenges that a school that wants to implement PT needs to know. In addition to the desired model, there is importance in a possible framework for enabling PT. Theoretically, this study presents a model for the process of PT in which fourth- and sixth-grade students are selected to be fellow teachers and undergo training towards teaching their peers. In doing so, the research contributes to the body of knowledge involved in PT in science classes in elementary school. The aforementioned research was conducted in a single school that advocates the Montessori-style school in one science class. This research environment also contributes to the professional literature. This study was conducted in a combined approach of quantitative and qualitative research. Therefore, the sample size is relatively small and includes two classes. It is necessary to examine the results of this study in other schools as well.

\section{REFERENCES}

Alerby, E. (2000). A way of visualising children's and young people's thoughts about the environment: $A$ study of drawings. Environmental Education Research, 6(3), 205-222. https://doi.org/10.1080/13504620050076713

Alsubaie, M. A. (2015). Hidden curriculum as one of current issue of curriculum. Journal of Education and Practice, 6(33), 125-128. https://files.eric.ed.gov/fulltext/EJ1083566.pdf

Arviv-Elyashiv, R., \& Gal, A. (2017). Hierarchy of needs of persistent mathematics and science teachers. American Journal of Educational Research, 5(7), 683693. https://doi.org/10.12691/education-5-7-1

Barraza, L., \& Walford, R. A. (2002). Environmental education: A comparison between English and Mexican school children. Environmental Education Research, 8(2), 171-186. https://doi.org/10.1080/13504620220128239

Boud, D. (2001). Peer learning in higher education: Learning from and with each other. In D. Boud, R. Cohen, \& J. Sampson (Eds.), Making the move to peer learning (pp. 1-20). Routledge.

Boud, D., \& Alison, L. (2007). 'Peer learning' as pedagogic discourse for research education. Studies in Higher Education, 30(5), 501-516. https://doi.org/10.1080/03075070500249138

Campolo, M., Maritz, C., \& Thielman, G. (2013). An evaluation of peer teaching across the curriculum: Student perspectives. International Journal of Therapies and Rehabilitation Research, 2, 1-7. https://doi.org/10.5455/ijtrr.00000016

Case, R. (1985). Intellectual development: Birth to adulthood. In Birth to adulthood. Academic press, London.

Cherewick, M., Lebu, S., Su, C., Richards, L., Njau, P. F., \& Dahl, R. E. (2021). Adolescent, caregiver and community experiences with a gender transformative, social emotional learning intervention. International Journal for Equity in Health, 20(1), 1-17. https://doi.org/10.1186/s12939021-01395-5

Cutter-Mackenzie, A., \& Rousell, D. (2018). Education for what? Shaping the field of climate change education with children and young people as co-researchers. Children's Geographies, 17(1), 90-104. https://doi.org/10.1080/14733285.2018.1467556

Eldén, S. (2013). Inviting the messy: Drawing methods and 'children's voices. Childhood, 20(1), 66-81. https://doi.org/10.1177/0907568212447243

Engels, D., Kraus, E., Obirei, B., \& Dethleffsen, K. (2018). Peer teaching beyond the formal medical curriculum. Advances in Physiology Education, 42(3), 439-448. https://doi.org/10.1152/advan.00188.2017

Espinoza, D., Saunders, R., Kini, T., \& Darling-Hammond, L. (2018). Taking the long view: State efforts to solve teacher shortages by strengthening the profession. Palo Alto, CA: Learning Policy Institute. https://learningpolicyinstitute.org/product/longview.

Fraenkel, J. R., Wallen, N. E., \& Hyun, H. H. (2012). How to design and evaluate research in education. McGrawHill.

Franz, N. K. (2015). The unfocused focus group: Benefit or bane? The Qualitative Report, 16(5), 1380-1388.

Gal, A. (2020). Active or passive - What do pre-service science teachers prefer in their professional training? World Journal of Educational Research, 7(1), 1-28. https://doi.org/10.22158/wjer.v7n1p81

Glaser, B., \& Strauss, A. (1967). The discovery of grounded theory: Strategies for qualitative research. Chicago: Aldine. https://doi.org/10.1177/0020764020922269

Griffiths, S., Houston, K., \& Lazenbatt, A. (1995). Enhancing student learning through peer tutoring in higher education. Coleraine: Educational Development Unit, University of Ulster.

Karamaroudis, S., Poulogiannopoulou, E., Sotiropoulos, M. G., Kalantzis, T., \& Johnson, E. O. (2020). Implementing change in neuroanatomy education: Organization, evolution, and assessment of a nearpeer teaching program in an undergraduate medical school in Greece. Anatomical Sciences Education, 13, 1-13. https://doi.org/10.1002/ase.1944 
Korner, M., \& Hopf, M. (2015). Cross-age peer tutoring in physics: Tutors, tutees, and achievement in electricity. International Journal of Science and Mathematics Education, 13(5), 1039-1063. https://doi.org/10.1007/s10763-014-9539-8

Kubiatko, M., Torkar, G., \& Rovnanova, L. (2017). The teacher as one of the factors influencing students' perception of biology as a school subject. Center for Educational Policy Studies Journal, 7(2), 127-140.

Lim, L. (2003). A case study on peer-teaching. Open Journal of Social Sciences, 2, 35-40.

Lockspeiser, T. M., O’Sullivan, P., Teherani, A., \& Muller, J. (2008). Understanding the experience of being taught by peers: The value of social and cognitive congruence. Advances in Health Sciences Education, 13(3), 361-372. https://doi.org/10.1007/s10459-0069049-8

Marshall, C. (2017). Montessori education: A review of the evidence base. Science of Learning, 2(1), 1-9. https://doi.org/10.1038/s41539-017-0012-7

Mckenna, L., \& French, J. (2011). Nurse education in practice a step ahead: Teaching undergraduate students to be peer teachers. Nurse Education in Practice, 11(2), 141-145. https://doi.org/10.1016/j.nepr.2010.10.003

Mennim, P. (2017). A discourse-based evaluation of a classroom peer teaching project. English Language Teaching, 71(1), 37-49. https://doi.org/10.1093/elt/ccw046

Neth, E. L., Caldarella, P., Richardson, M. J., \& Heath, M. A. (2020). Social-emotional learning in the middle grades: A mixed-methods evaluation of the strong kids program. RMLE Online, 43(1), 1-13. https://doi.org/10.1080/19404476.2019.1701868

Newman, J. Z. (2020). Supporting the out-of-school time workforce in fostering intentional social and emotional learning. Journal of Youth Development, 15(1), 239-265. https://doi.org/10.5195/jyd.2020.807

Nind, M., Coverdale, A., \& Croydon, A. (2020). Learning from each other in the context of personalisation and self-build social care. Disability and Society, 1-21. https://doi.org/10.1080/09687599.2020.1812378

Olle, C., \& Durning, S. (2007). Peer teaching in medical education: Twelve reasons to move from theory to practice. Medical Teacher, 29(6), 591-599. https://doi.org/10.1080/01421590701606799

Omasta, M., Graham, M., Milling, S. L., Murray, E., Jensen, A. P., \& Siebert, J. J. (2020). Social emotional learning and the national core arts standards: A crossdisciplinary analysis of policy and practices. Arts Education Policy Review, 1-13. https://doi.org/10.1080/10632913.2020.1773366

Orson, C. N., McGovern, G., \& Larson, R. W. (2020). How challenges and peers contribute to social-emotional learning in outdoor adventure education programs.
Journal of Adolescence, 81, 7-18. https://doi.org/10.1016/j.adolescence.2020.02.014

Osborne, J., Simon, S., \& Collins, S. (2003). Attitudes towards science: A review of the literature and its implications. International Journal of Science Education, 25(9), 1049-1079. https://doi.org/10.1080/0950069032000032199

Pålsson, Y., Mårtensson, G., Leo, C., Ädel, E., \& Engström, M. (2017). Nurse education today a peer learning intervention for nursing students in clinical practice education: A quasi-experimental study. Nurse Education Today, 51, 81-87. https://doi.org/10.1016/j.nedt.2017.01.011

Pidgeon, N., \& Henwood, K. (1996). Grounded theory: Practical implementation. In J. T. R. Richardson (Ed.), Handbook of Qualitative Research Methods (pp. 86101). Leicester: The British Psychological Society Books.

Pinchumphonsang, S., \& Chanchalor, S. (2020). The development of social emotional learning programs in a cross-cultural elementary classroom. International Journal of Innovation and Learning, 27(1), 58-78. https://doi.org/10.1504/IJIL.2020.103888

Potvin, P., \& Hasni, A. (2014). Analysis of the decline in interest towards school science and technology from grades 5 through 11. Journal of Science Education and Technology, 23(6), 784-802. https://doi.org/10.1007/s10956-014-9512-x

Räisänen, M., Postareff, L., \& Lindblom-Ylänne, S. (2020). Students' experiences of study-related exhaustion, regulation of learning, peer learning and peer support during university studies. European Journal of Psychology of Education, 1-23. https://doi.org/10.1007/s10212-020-00512-2

Secomb, J. (2008). A systematic review of peer teaching and learning in clinical education. Journal of Clinical Nursing, 17, 703-716. https://doi.org/10.1111/j.13652702.2007.01954.x

Şen, A. (2010). Effects of peer teaching and microteaching on teaching skills of pre-service physics teachers. Education and Science, 35(155), 78-88.

Shkedi, A. (2004). Second-order theoretical analysis: A method for constructing theoretical explanation. International Journal of Qualitative Studies in Education, 17(5), 627-646. https://doi.org/10.1080/0951839042000253630

Shkedi, A. (2005). Multiple case narrative: A qualitative approach to studying multiple populations. John Benjamins Publishing.

Stigmar, M. (2016). Peer-to-peer teaching in higher education: A critical literature review. Mentoring and Tutoring: Partnership in Learning, 24(2), 124-136. https://doi.org/10.1080/13611267.2016.1178963

Strauss, A., \& Corbin, J. (1990). Basics of Qualitative 
Research: Grounded Theory Procedures and Techniques. Sage Publications.

Sutcher, L., Darling-Hammond, L., \& Carver-Thomas, D. (2019). Understanding teacher shortages: An analysis of teacher supply and demand in the united states. Education Policy Analysis Archives, 27(35), 1-40. https://doi.org/10.14507/epaa.27.3696

Topping, K. J. (2005). Trends in peer learning. Educational Psychology, 25(6), 631-645. https://doi.org/10.1080/01443410500345172

Tyng, C. M., Amin, H. U., Saad, M. N. M., \& Malik, A. S. (2017). The influences of emotion on learning and memory. Frontiers in Psychology, 8, 1-22. https://doi.org/10.3389/fpsyg.2017.01454

Van Manen, M. (2016). Researching lived experience: Human science for an action sensitive pedagogy. Routledge.

Vedder-Weiss, D., \& Fortus, D. (2011). Adolescents' declining motivation to learn science: Inevitable or not? Journal of Research in Science Teaching, 48(2), 199-216. https://doi.org/10.1002/tea.20398

Vygotskiĭ, L. S. (1978). Mind in society: The development of higher psychological processes. Cambridge, MA: Harvard University Press.

Wiersma, W., \& Jurs, S. G. (2005). Research methods in education: An introduction. Ally and Bacon.

Yang, C., Chan, M. K., \& Ma, T. L. (2020). School-wide social emotional learning (SEL) and bullying victimization: Moderating role of school climate in elementary, middle, and high scho ols. Journal of School Psychology, 82, 49-69. https://doi.org/10.1016/j.jsp.2020.08.002 